\title{
EXPERIMENTAL STUDY OF FILLETS TO REDUCE CORNER EFFECTS IN AN OBLIQUE SHOCK-WAVE/BOUNDARY-LAYER INTERACTION
}

\begin{abstract}
by
STEFANIE M. HIRT

Submitted in partial fulfillment of the requirements for the degree of
\end{abstract}

\author{
Master of Science \\ Mechanical and Aerospace Engineering Department \\ CASE WESTERN RESERVE UNIVERSITY
}

January, 2015 


\title{
CASE WESTERN RESERVE UNIVERSITY \\ SCHOOL OF GRADUATE STUDIES
}

\author{
We hereby approve the thesis of \\ STEFANIE M. HIRT \\ Candidate for the degree of Master of Science
}

Committee Chair

JAIKRISHNAN R. KADAMBI

Committee Member

PAUL BARNHART

Committee Member

YASUHIRO KAMOTANI

Date of Defense

November 13, 2014

*We also certify that written approval has been obtained for any proprietary material contained therein. 
The work entitled "Experimental Study of Fillets to Reduce Corner Effects in an Oblique Shock-Wave/Boundary-Layer Interaction" was prepared as part of my official duties as an employee of the U.S. Government and, in accordance with 17 U.S.C. 105 is not available for copyright protection in the United States. All foreign rights reserved. 
I would like to dedicate my thesis to Isaac Hirt, for putting up with me through it all. 


\section{Table of Contents}

$\begin{array}{ll}\text { ABSTRACT } & 1\end{array}$

I. INTRODUCTION 2

II. NOMENCLATURE 6

$\begin{array}{lll}\text { III. } & \text { BACKGROUND } & 8\end{array}$

A. CORner Flow $\quad 8$

B. CORNER SHOCK INTERACTIONS 9

C. Fillet Applications 10

D. Other Corner Control $\quad 12$

$\begin{array}{ll}\text { IV. } & 13\end{array}$

$\begin{array}{ll}\text { A. FACILITY } & 13\end{array}$

B. TEST HaRdWARE 15

C. INSTRUMENTATION 20

D. EXPERIMENTAL UNCERTAINTY

$\begin{array}{ll}\text { E. Test CASES } & 25\end{array}$

$\begin{array}{llr}\text { V. } & \text { ANALYSIS METHODOLOGY } & 28\end{array}$

$\begin{array}{ll}\text { A. Data AVeraging } & 28\end{array}$

B. IDENTIFYING THE WALl Location 29

C. PREPROCESSING 32

D. Calculation of Properties at the Measurement Plane 33 
E. Edge Conditions 34

F. Boundary-Layer Parameters

$\begin{array}{lll}\text { VI. } & \text { RESULTS } & 36\end{array}$

A. UPSTREAM FlOW FIELD 36

$\begin{array}{lr}\text { B. BASELINE } & 39\end{array}$

C. Fillet Test Matrix 46

D. Fillets With Micro-RAMp Flow CONTROL 61

$\begin{array}{lll}\text { VII. } & \text { CONCLUSIONS AND FUTURE WORK }\end{array}$

$\begin{array}{ll}\text { BIBLIOGRAPHY } & 67\end{array}$ 


\section{List of Tables}

TABLE 1. PROPAGATION OF UNCERTAINTY FOR THREE FLOW CONDITIONS.

TABLE 2. FILLET CONFIGURATIONS. 


\section{List of Figures}

FIgURE 1. THREE-DIMENSIONAL REPRESENTATION OF AN INVISCID APPROXIMATION OF THE REFLECTING OBLIQUE SHOCK INTERACTION.

FIGURE 2. SCHEMATIC OF SECONDARY FLOW STRUCTURE IN THE CORNER.

FiguRE 3. OIL FLOW VISUALIZATION FOR A MACH 1.6 NORMAL SHOCK; FROM CHRISS [28].

FIGURE 4. COMPARISON OF INLET TOTAL PRESSURE RECOVERY CONTOURS FOR SUPERSONIC SCOOP INLET AT THE SAME OPERATING POINT (A) WITHOUT CORNER FILLETS AND (B) WITH CORNER FILLETS; FROM VALERINO [31].

FiguRE 5. PHOTOGRAPH OF THE 15 CM X 15 CM SUPERSONIC WIND TUNNEL.

FIGURE 7. SCHEMATIC SHOWING THE POSITION OF THE SHOCK GENERATOR AND FILLET CONFIGURATIONS.

FiguRE 8. PHOtOGRAPH OF FILLETS INSTALLED IN THE CORNERS OF THE TEST SECTION, LOOKING DOWNSTREAM.

Figure 9. ILLUSTRATION OF THE THREE FILlet PARAMETERS THAT WERE VARIED.

FIGURE 10. LOCATION OF STATIC PRESSURE TAPS. EACH DOT REPRESENTS A TAP LOCATION.

FIGURE 11. ARRAY OF MEASURED PITOT PRESSURE LOCATIONS.

FIGURE 12. MICRO-RAMP GEOMETRY PARAMETERS.

Figure 13. SAMPLE OF the PLOT USED to ESTIMATE THE WALL TOUCH LOCATION.

FiguRE 14. MACH CONTOURS FOR THE UPSTREAM PLANE MEASURED AT $\mathrm{X}=40.2 \mathrm{CM}$.

FIGURE 15. ISOVELOCITY CONTOURS FOR THE UPSTREAM PLANE MEASURED AT X $=40.2 \mathrm{cM}$.

FiguRE 16. BOUNDARY-LAYER THICKNESS AT EACH PROFILE LOCATION FOR THE UPSTREAM CASE $(X=40.2$ CM). DOTTED LINE INDICATES MEAN VALUE ALONG THE FLOOR.

FIGURE 17. INCOMPRESSIBLE SHAPE FACTOR AT EACH PROFILE LOCATION FOR THE UPSTREAM CASE. DOTTED LINE INDICATED MEAN VALUE ALONG THE FLOOR.

FiguRE 18. OIL FLOW VISUALIZATION (AT TOP) AND SCHLIEREN IMAGE (AT BOTTOM) FOR THE BASELINE CONFIGURATION, MACH

FIGURE 19. COMPARISON OF OIL FLOW VISUALIZATION TO COMPUTATIONAL RESULTS FOR A SIMILAR CONFIGURATION BY BENEK

ET AL. [4] 
FIGURE 20. STATIC PRESSURE DISTRIBUTION ON THE TUNNEL CENTERLINE FOR THE BASELINE CONFIGURATION.

FIGURE 21. MACH NUMBER CONTOURS FOR THE BASELINE CASE.

FIGURE 22. ISOVELOCITY CONTOURS FOR THE BASELINE CASE.

FIGURE 23. BOUNDARY-LAYER THICKNESS AT EACH PROFILE LOCATION FOR THE BASELINE CASE.

FIGURE 24. INCOMPRESSIBLE SHAPE FACTOR AT EACH PROFILE LOCATION FOR THE BASELINE CASE.

FIGURE 25. NORMALIZED ISOVELOCITY CONTOURS FOR THE FILLET CONFIGURATIONS.

FIGURE 26. BOUNDARY-LAYER THICKNESS AT EACH PROFILE LOCATION FOR EACH OF THE FILLET CONFIGURATIONS.

FIGURE 27. INCOMPRESSIBLE SHAPE FACTOR AT EACH PROFILE LOCATION FOR EACH OF THE FILLET CONFIGURATIONS.

FIGURE 28. BOUNDARY-LAYER THICKNESS ALONG THE CORNER BISECTOR VERSUS FILLET RADIUS.

FIGURE 29. BOUNDARY LAYER EDGE LOCATION MEASURED ALONG THE CORNER BISECTOR VERSUS FILLET RADIUS.

FIGURE 30. BOUNDARY-LAYER THICKNESS AT THE TUNNEL CENTERLINE VERSUS FILLET RADIUS.

FIGURE 31. INCOMPRESSIBLE SHAPE FACTOR FOR THE CORNER PROFILE VERSUS FILLET RADIUS.

FIGURE 32. INCOMPRESSIBLE SHAPE FACTOR AT THE TUNNEL CENTERLINE VERSUS FILLET RADIUS

FIGURE 29. OIL FLOW VISUALIZATION FOR TWO FILLET CONFIGURATIONS COMPARED TO THE BASELINE. THE SOLID LINE INDICATES THE INVISCID SHOCK IMPINGEMENT LOCATION. THE DASHED LINES INDICATE THE EXTENT OF THE SEPARATION REGION FOR THE BASELINE CASE.

FIGURE 33. NORMALIZED ISOVELOCITY CONTOURS COMPARING WITH AND WITHOUT MICRO-RAMPS.

FIGURE 34. BOUNDARY-LAYER THICKNESS AT EACH PROFILE LOCATION FOR THE MICRO-RAMP CASE. 
The author would like to gratefully acknowledge the support of the NASA Fundamental Aeronautics Program, specifically the Aeronautical Sciences and High Speed Projects for their support of this work. Additionally, the author would like to thank the facility team at the $15 \mathrm{~cm} \times 15 \mathrm{~cm}$ supersonic wind tunnel for their help, and David Davis, Khairul Zaman, and Mary Jo Long-Davis for their editing assistance. Finally, the author wishes to express gratitude to the members of her thesis committee:

Paul Barnhart, Yasuhiro Kamotani, and especially her advisor, Jaikrishnan Kadambi. 
Experimental Study of Fillets to Reduce Corner Effects in an Oblique ShockWave/Boundary-Layer Interaction

Abstract

By

STEFANIE M. HIRT

A series of tests were conducted in the $15 \mathrm{~cm} \times 15 \mathrm{~cm}$ supersonic wind tunnel at NASA Glenn Research Center that focused on corner effects of an oblique shockwave/boundary-layer interaction. In an attempt to control the interaction in the corner region, eight corner fillet configurations were tested. Three parameters were considered for the fillet configurations; the radius, the fillet length, and the taper length. Fillets effectively reduced the boundary-layer thickness in the corner; however, there was an associated penalty in the form of increased boundary-layer thickness at the tunnel centerline. Larger fillet radii caused greater reductions in boundary-layer thickness along the corner bisector. To a lesser, but measureable, extent, shorter fillet lengths resulted in thinner corner boundary layers. Overall, of the configurations tested, the largest radius resulted in the best combination of control in the corner, evidenced by a reduction in boundary-layer thickness, coupled with minimal impacts at the tunnel centerline. 


\section{Introduction}

When a shock-wave interacts with the low-momentum fluid in a viscous boundary layer, the pressure rise associated with the shock wave causes the boundary layer to thicken or, for stronger shocks, causes flow separation. This interaction occurs in a wide range of high speed flows such as flow over transonic airfoils and flow through propulsion flowpaths.

Because the presence of these interactions is common, much attention has been devoted both to understanding the physics of such flows as well as developing means to control the effects of the interaction. This research generally takes the form of simplified unit problems where the phenomena can be studied in a more easily understood environment. Some common unit problems which have been used to investigate shockwave/boundary-layer interactions (SWBLI) include the swept fin problem [1, 2], impinging oblique shock interactions $[3,4]$, compression ramp interactions $[5,6]$, normal shock interactions [7, 8], and a symmetric wedge compression corner $[9,10]$.

Many of these unit problem experiments are conducted in small wind tunnels with rectangular cross sections. There are several reasons for using a rectangular cross section, including ease of model integration and change out, ease of incorporating optical diagnostic techniques, and similarity to certain flight geometries. However, when a rectangular cross section is used, it introduces the complication of corners where two viscous boundary layers interact. 
In the present study, an oblique shock wave was generated and reflected off of the bottom wall of a small scale supersonic wind tunnel with a square cross section, as shown in Figure 1. This configuration incorporates three distinct unit problems: the swept fin interaction on the sidewalls, an impinging/reflecting oblique shock-wave interaction on the floor, and the corner flow interaction.

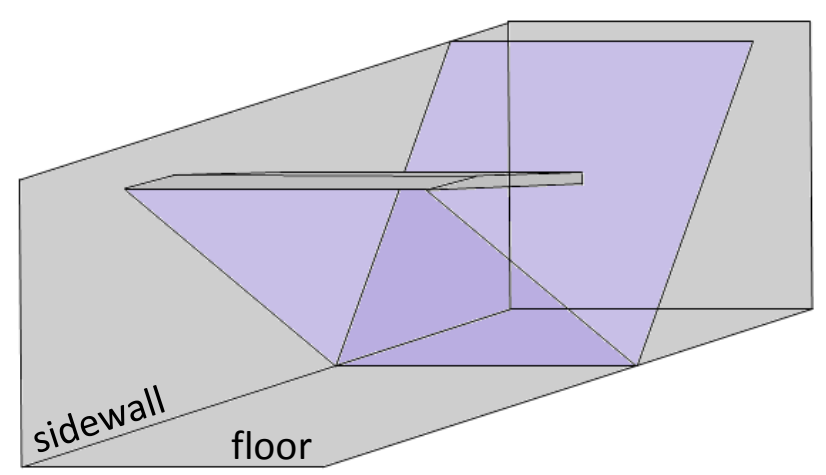

FIGURE 1. THREE-DIMENSIONAL REPRESENTATION OF AN INVISCID APPROXIMATION OF THE REFLECTING OBLIQUE SHOCK INTERACTION.

Looking first at the interaction on the sidewall of the tunnel, the swept fin interaction causes the flow to turn parallel to the shock generator incidence angle and drives additional low-momentum fluid toward the floor of the wind tunnel and into the corner region. Because of the subsonic layer on the sidewall, this flow turning begins upstream of the shock wave.

A second interaction along the floor of the tunnel is the impinging shock that spans the tunnel width and subjects the flow to the pressure rise of the shock and its reflection. In a viscous flow, the pressure rise occurs over some interaction length. 
The interaction of the shock wave with the corner flow is the focus of this study. Along the corner bisector, the subsonic layer is large compared to the boundary layers along the centerline of the tunnel span. The swept fin interaction introduces an additional mass of low-momentum fluid to the corner region, as noted earlier. Additionally, as with the impinging shock interaction, the corner flow region is subjected to a strong streamwise adverse pressure gradient over a short streamwise extent.

The effects of all three interactions - the additional low-momentum fluid from the sidewall boundary layer, the large pressure rise of the shock and reflection, and the already large subsonic layer in the corner - combine to cause the flow in the corner to separate earlier than either the side or bottom walls. This recirculation extends somewhat upstream of the centerline interaction region, and the flow experiences the separation region as an aerodynamic blockage which creates a weak conic compression in the flow. The aerodynamic blockage and the compression wave affect the shape and magnitude of the impinging shock interaction across the entire span of the tunnel.

In this investigation, fillets were introduced into the corners of the wind tunnel. It was expected that the fillets would reduce the thickness of the subsonic layer in the corner, thereby improving the boundary-layer properties in the corner and increasing the resistance of the corner to separation. The geometric properties of the fillets were varied to determine the effect of the fillet radius, fillet length, and the length of the taper from a square corner to the fillet radius on the effectiveness of the fillets. Additionally, one 
case was tested which incorporated micro-ramp vortex generators on the tunnel floor coupled with the largest fillet configuration.

The remainder of this report documents the effort in detail. The paper is structured as follows.

- Chapter 2 presents the nomenclature used throughout this document.

- Chapter 3 presents background information relevant to the current problem based on a review of the literature.

- Chapter 4 presents the experimental setup, including details on the facility, instrumentation, experimental uncertainties, test hardware, and test matrix.

- Chapter 5 presents a description of the data analysis methodology that was used.

- Chapter 6 presents the experimental results obtained.

- Chapter 7 presents the conclusion of the present study and suggestions for future work. 


\section{Nomenclature}

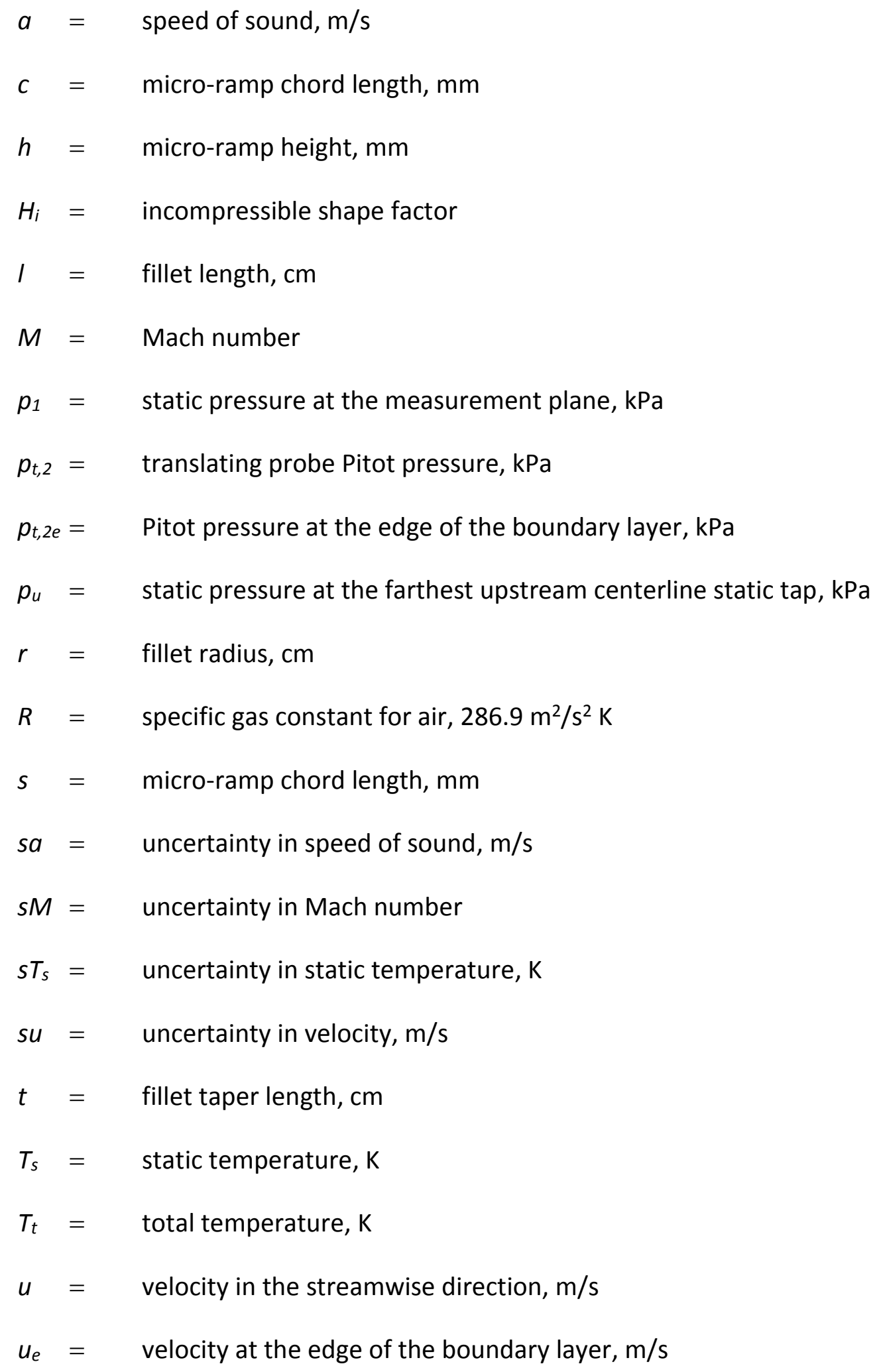




$$
\begin{aligned}
& u_{\infty}=\text { freestream velocity, } \mathrm{m} / \mathrm{s} \\
& \alpha=\text { micro-ramp vertex half-angle, degrees } \\
& \gamma=\text { ratio of specific heats, } 1.4 \\
& \delta=\text { boundary-layer thickness, } \mathrm{cm} \\
& \delta_{c}=\text { boundary-layer edge location measured along the corner bisector }
\end{aligned}
$$

$\delta_{i}^{*}=$ incompressible boundary-layer displacement thickness, $\mathrm{cm}$

$\theta_{l}=$ incompressible boundary-layer momentum thickness, $\mathrm{cm}$ 


\section{Background}

\section{A. Corner Flow}

In regions of flow where two surfaces come together to form a right angle corner, the viscous boundary layers formed on each surface interact. A number of subsonic [11, 12 , $13,14,15,16,17,18]$ and supersonic $[19,20,21]$ experimental and computational studies have focused on understanding this flow field.

Findings included that the corner layer could not be modeled in the same way used for a viscous boundary layer on a flat surface $[11,12,13,14,21,22]$. This is due in large part to the fact that corner flows are inherently three-dimensional.

In the absence of transverse pressure gradients, corner secondary flow of Prandtl's second kind develops [23], with velocities vectoring toward the wall along the corner bisector and away from the corner along the walls, as shown in Figure 2. Maximum secondary flow velocities of about $3 \%$ of the freestream velocity were reported by Mojola and Young [16]. This secondary flow causes isovelocity lines to be distorted toward the vertex along the corner bisector $[18,19]$.

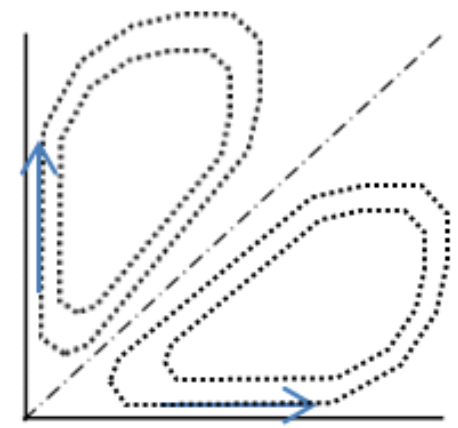

FIGURE 2. SCHEMATIC OF SECONDARY FLOW STRUCTURE IN THE CORNER. 


\section{B. Corner Shock Interactions}

Several configurations have been examined to look at what happens when a shockwave interacts with the flow in a corner, including both oblique and normal shock-waves. For an oblique shock-wave interaction, the corner region separates first due to the thick subsonic region and results in a highly three-dimensional interaction [24]. The thick subsonic layer also allows the influence of the interaction to extend farther upstream, which is observed as a rise in the static pressure for profiles near the corner [2], and this upstream influence acts as an aerodynamic blockage to the flow which generates compression waves $[25,26]$.

These compression waves propagate across the tunnel span and distribute the pressure rise, which reduces the likelihood of flow separation in the affected region [4]. Oil flow confirms that the corner interaction can have a major effect on a large part of the "two-dimensional" flow field [2].

For a normal shock-wave, interaction with viscous walls gives the shock-wave a threedimensional shape [27]. Like the oblique shock case, the interaction extends farther upstream in the corner regions than at the centerline as can be seen in Figure 3, which shows oil flow visualization captured by Chriss [28] for a normal shock-wave at Mach 1.6. At this Mach number, the corner interactions comprised a large portion of the flow field. Such large corner interactions act to bifurcate the shock-wave, which distributes the pressure rise [29]. Additionally, for normal shock-wave interactions, the corner 
interactions have been shown to have a large impact away from the corners - impacting the separation extent at the centerline [30].

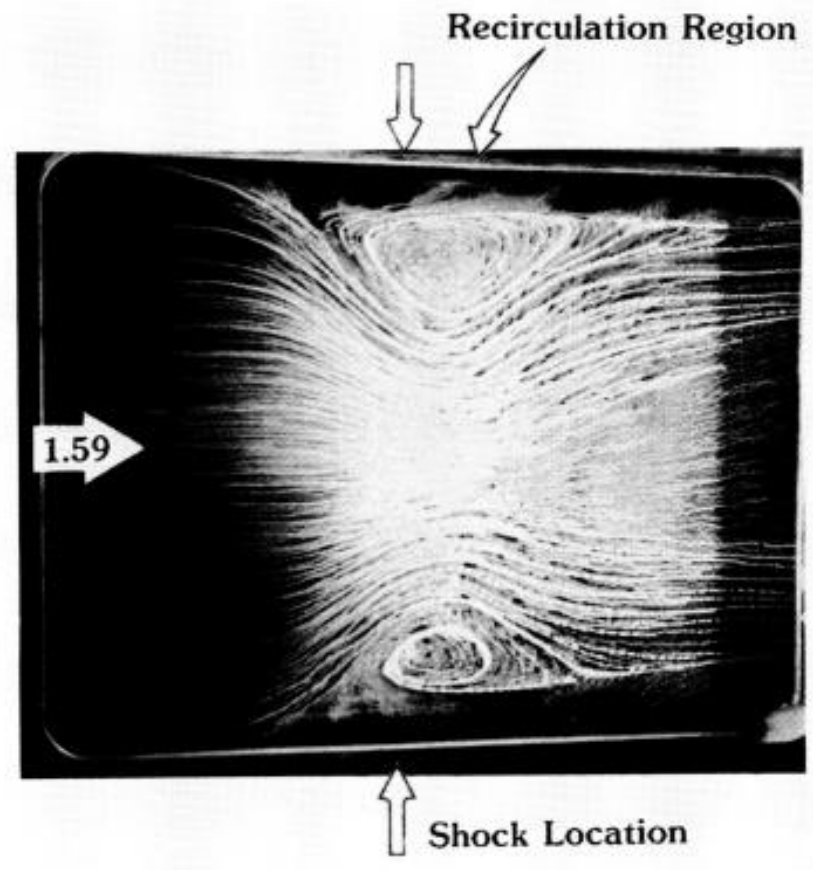

Figure 3. OIL fLOW VISUALIZATION FOR A MACH 1.6 NORMAL SHOCK; FROM ChRISS [28].

\section{Fillet Applications}

Fillets have been studied as a possible means to control corner effects in many configurations with varying effectiveness.

An early supersonic inlet study by Valerino [31] found that incorporating fillets into the corners of the inlet could increase the critical total pressure recovery or extend the stable operating range depending on the Mach number. Fillets also made the total pressure recovery distribution more uniform as seen in Figure 4. Additionally, tests of a subsonic serpentine inlet showed that a small radius in the corners gave the lowest 
distortion [32]. On the other hand, a different supersonic inlet configuration tested at low speeds found corner fillets to have little effect [33].

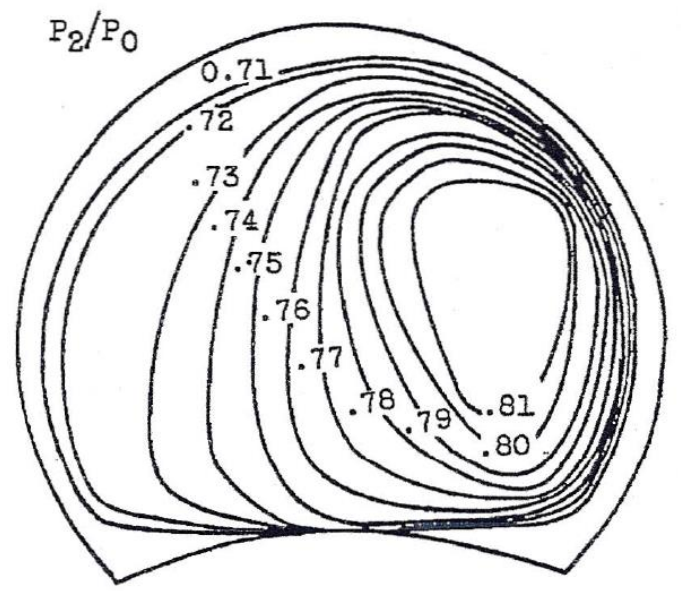

(a) Inlets without corner fillets. Static- to totel-pressure ratio, 0.729 ; mass flow ratio, 0.880 .

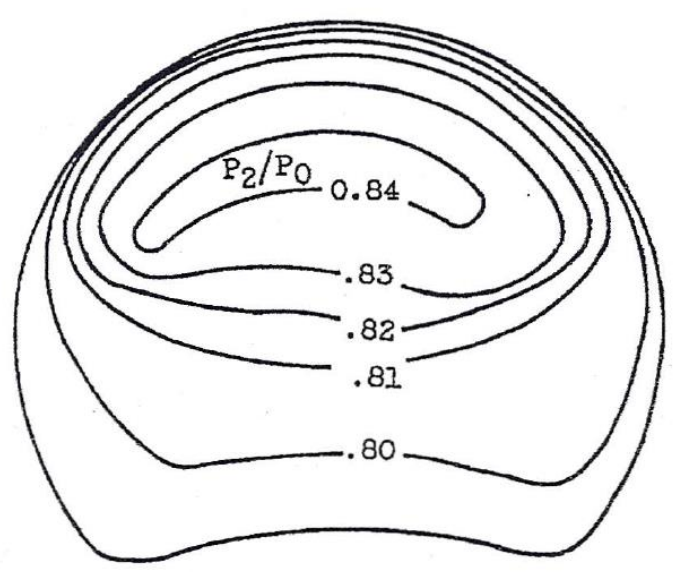

(b) Inlets with corner fillets. Static- to total-pressure ratio, 0.728 ; mass flow ratio, 0.887 .

FIGURE 4. COMPARISON OF INLET TOTAL PRESSURE RECOVERY CONTOURS FOR SUPERSONIC SCOOP INLET AT THE SAME OPERATING POINT (A) WITHOUT CORNER FILLETS AND (B) WITH CORNER FILLETS; FROM VALERINO [31].

A computational study of a supersonic rectangular nozzle found that corner rounding of $10 \%$ of the nozzle half width effectively controlled the corner vortex and instability [34].

One test of fillets on a wing body junction at low speed with the fillet wrapped around the entire base of the wing did not prevent separation, but merely acted to increase the effective radius of the leading edge of the wing [35]. 


\section{Other Corner Control}

Previous studies have considered several ways to mitigate the separation in corner shock-wave interactions. Bleed has been successfully used to control the corner interaction $[29,36,37]$. Removing a portion of the low momentum flow from the corner region improves the resistance to separation. However, in one case the required flow rate was too high to be considered favorable [36], and in another, the bleed showed little effect [38].

Aerodynamic fences have been used in supersonic wind tunnel testing where the interest is in making measurements on the centerline. The fences, placed parallel to the sidewalls, isolate the center region of the test section from the corner interaction at the tunnel sidewalls. A new, thin boundary layer develops along the fences, which approximates an inviscid wall [39, 40, 41, 42].

Vortex generators have been studied in an attempt to use mixing to increase the near wall velocity in the corner region to reduce corner separation, but generally have not been found to be effective at controlling the flow in corners $[29,36]$.

Recently, chamfers applied to the corners of the flow domain in a computational study were considered as a way to limit the extent of the corner effects for an oblique shock interaction by blocking the migration of flow from the sidewall swept fin interaction into the corner. The effectiveness was shown to be similar to that in a computed bleed comparison case for controlling the corner interaction but avoided the need for mass removal [26]. 


\section{Experimental Setup}

\section{A. Facility}

The experimental testing for this study was completed in the $15 \mathrm{~cm} \times 15 \mathrm{~cm}$ supersonic wind tunnel, shown in Figure 5, in the Engine Research Building of the NASA Glenn Research Center. This tunnel is a continuous flow facility with air supplied at $377 \mathrm{kPa}$ and exhausted to a vacuum system which maintains an absolute pressure of $13.8 \mathrm{kPa}$. A valve upstream in the inflow line regulates the incoming total pressure. During this test, the pressure was controlled to maintain a Reynolds number of $13.1 \mathrm{E} 6 / \mathrm{m}$.

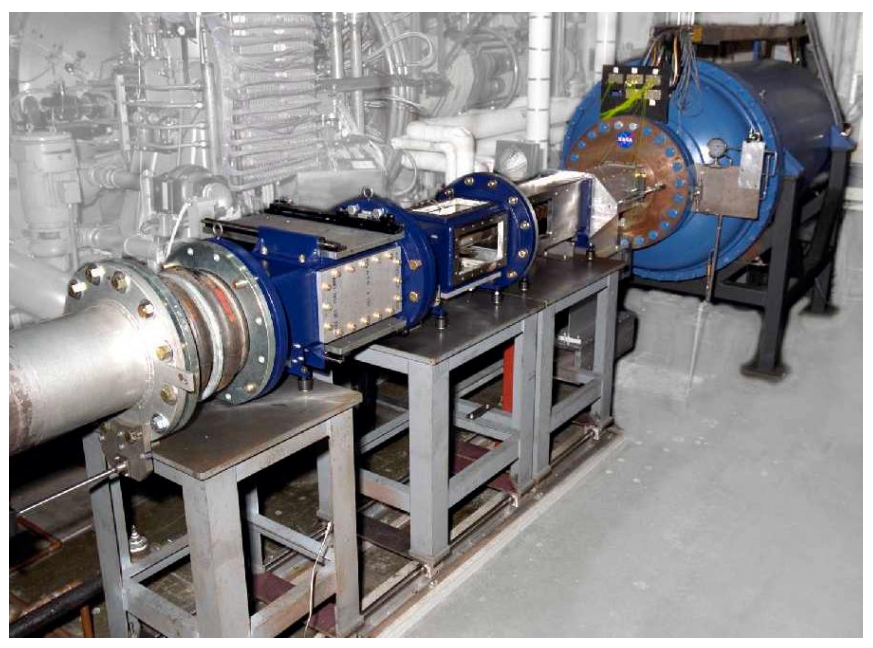

FigURE 5. PHOTOGRAPH OF THE 15 CM X 15 CM SUPERSONIC WIND TUNNEL.

The flow enters the wind tunnel through a large plenum, in which the velocity is very low. The low speed, as well as flow conditioning screens and straighteners, in the plenum improves the flow quality. The flow exits the plenum through a bell mouth contraction which transitions the duct from round to square. 
Downstream of the plenum, a fixed geometry converging-diverging nozzle accelerates the flow to a supersonic condition. The top and bottom walls of the nozzle are contoured to provide the required area change, whereas the sidewalls are flat. For this test, the facility fixed wall Mach 2 nozzle was used, which provided a measured Mach number at the nozzle exit during the test of 1.98 .

The test section is a $15 \mathrm{~cm}$ square constant area duct extending $71 \mathrm{~cm}$. A photograph of the test section is shown in Figure 6 with the $x-, y-$, and $z$-directions indicated. The coordinate system origin for this test was chosen such that $x=0 \mathrm{~cm}$ at the test section entrance, $y=0 \mathrm{~cm}$ on the bottom wall, and $z=0 \mathrm{~cm}$ on the left wall when looking downstream.

The test section includes four removable wall sections, one on each wall, which can be modified as needed for testing. For this test, sidewall inserts were used which had large plexiglass windows. The top wall insert had a smaller glass window. Two different inserts were used for the bottom wall during different phases of testing. One was a blank, and the other was instrumented with static taps, which will be described in more detail later.

The aft end of the test section mates with a duct that has a $23.5 \mathrm{~cm}$ square cross section. Incorporated in this section is a translation mechanism that allows for remotely controlled translation of a probe in the $y$ - and z-directions, and manual translation in the $x$-direction. 
The nozzle block, test section, and translation section were each aligned to be within 0.05 degrees of horizontal in all directions prior to testing.

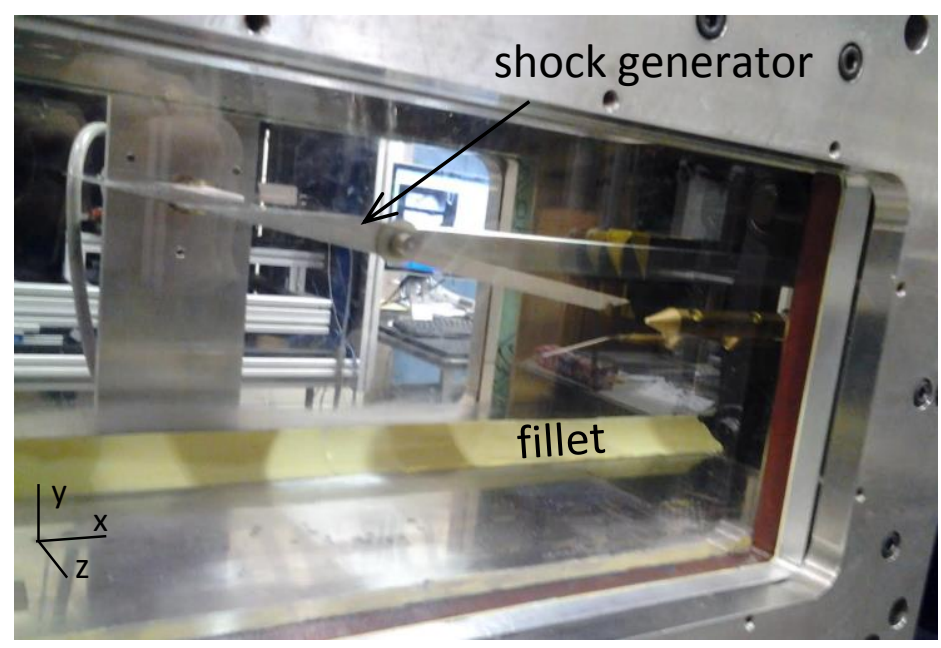

Figure 6. PHOTOGRAPH OF THE TEST HARDWARE INSTALLED IN THE TEST SECTION. (AXES SHOWN TO INDICATE DIRECTION, NOT ORIGIN LOCATION.)

\section{B. Test Hardware}

The test hardware for this study included an oblique shock generator plate and several fillet configurations. The shock generator and a fillet configuration can be seen installed in the test section in Figure 6.

A schematic of the layout of the test hardware in the test section is shown in Figure 7. Two representative fillet configurations are shown in red and green, representing the largest and smallest configurations tested. The blue dashed line indicates the undisturbed boundary-layer thickness measured at an x-location of $40.2 \mathrm{~cm}$. The oblique shock generator plate, as well as the shock and the leading edge of the expansion fan it 
creates are shown in dotted black lines in the figure. The rectangle shown represents the extent of the sidewall plexiglass windows.

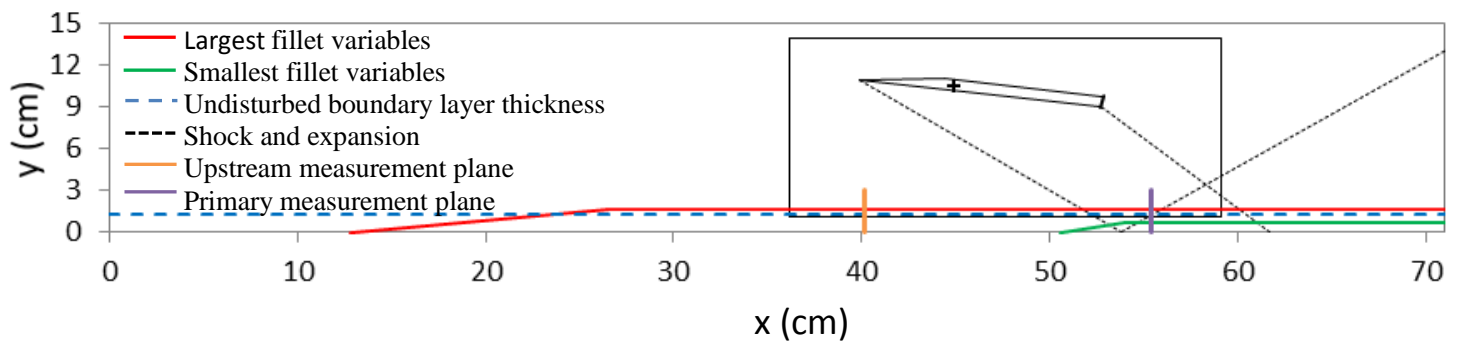

FIGURE 7. SCHEMATIC SHOWING THE POSITION OF THE SHOCK GENERATOR AND FILLET CONFIGURATIONS.

Shock Generator

To create an oblique shock-wave interaction, a flat plate with a sharp leading edge was used that spanned the entire tunnel. On the sides of the plate, pins extended into the plexiglass windows to allow the plate to pivot. The aft end of the plate was connected by a bar to an electric motor mounted in the translation section that controlled the plate angle.

The location of the shock generator plate can be seen in Figure 7. The test data were collected with the shock generator at 8.5 degrees. However, the tunnel would not start with the plate at that angle, so during startup, the angle was set at approximately 6 degrees and then remotely actuated to the test setting. At 8.5 degrees, the shock generator leading edge location was at $x=40.0 \mathrm{~cm}$, which led to an inviscid shock impingement location of $x=53.8 \mathrm{~cm}$. 
The length of the shock generator plate was chosen such that it was long enough that the expansion fan from the aft end of the plate didn't interfere with the measurements, but short enough so that blockage from the plate at 8.5 degrees didn't introduce a normal shock in the test section.

Fillets

The fillets for this test were created using a moldable material, EXAMIX'M NDS. A study was conducted by Braafladt [43] which looked at ten potential materials for use in this application. EXAMIX'M NDS is marketed for dental applications and is primarily used as an impression material. Because of this, it is designed to hold its shape within a tight tolerance as it cures. That property combined with a short cure time, ease of cleanup, and low surface roughness were the primary factors that lead to its selection.

Initially, conducting the test with metal fillets was considered, but for the smallest radius there was concern that there would not be enough material for a fastener to thread into. Additionally, there was more potential for damage if a metal fillet were to detach during the test compared to a moldable fillet.

The fillets were installed with a linear taper from the square corner of the test section to the full radius of the fillet. The radius then remained constant from that point to the end of the test section. Fillets were only applied to the two bottom corners of the test section as shown in Figure 8, which is where measurements were taken. 


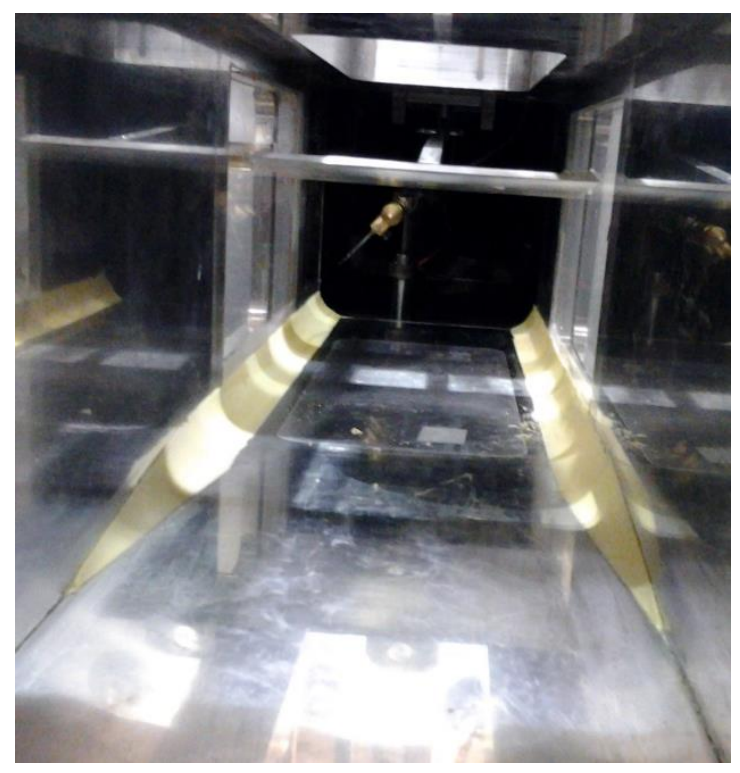

FiguRE 8. PHOTOGRAPH OF FILLETS INSTALLED IN THE CORNERS OF THE TEST SECTION, LOOKING DOWNSTREAM.

Figure 9 is a close up of the fillet region from Figure 7, which shows the three geometric variables of the fillets that were changed during the test: the fillet radius, $r$; the fillet length, l; and the taper length, $t$.

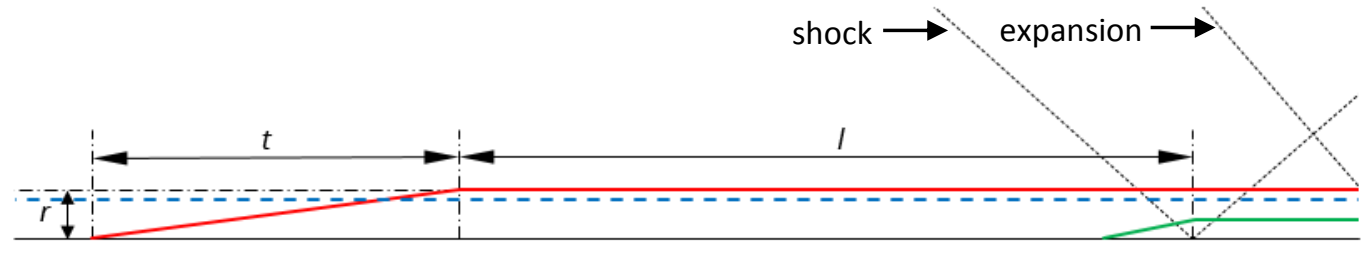

FiguRE 9. ILLUSTRATION OF THE THREE FILLET PARAMETERS THAT WERE VARIED.

The fillet radii tested ranged from 0.64 to $1.59 \mathrm{~cm}$. Based on boundary-layer thickness measurements at the tunnel centerline obtained in previous tests, these radii covered a 
range of approximately $r / \delta=1 / 3$ to $r / \delta=4 / 3$. The area change for the largest fillets resulted in a test section cross section that was $0.48 \%$ smaller than the square cross section. This area change resulted in the test section Mach number being reduced from 1.98 to 1.97 when fillets with the largest radius were installed.

The fillet length, $I$, was measured from the start of the full radius to the inviscid shock impingement location, as shown in Figure 9. The fillet lengths tested ranged from $0 \mathrm{~cm}$ to $27.4 \mathrm{~cm}$. In terms of expected boundary-layer thickness, this equates to a range from $I / \delta=0$ to $I / \delta=24$

The taper length, $t$, was the distance over which the corner transitioned from the square corner of the test section to the full fillet radius. Taper lengths of $3.4 \mathrm{~cm}$ and 13.7 $\mathrm{cm}$ were tested, representing an expected range of $t / \delta=3$ and $t / \delta=12$.

The fillets were formed in two sections: the taper, and the constant radius section. The constant radius section was formed by applying the material to the corner and using a metal cylinder of the desired radius as a mold. Tape was placed on the tunnel wall a distance of the radius away from the corner prior to applying the EXAMIX ${ }^{\mathrm{TM}}$ NDS. This allowed any excess material to be peeled away after it cured.

The taper section was formed in the same way except that a rapid prototype mold for the transition was used instead of a cylinder. After both sections were formed, sand paper was used to smooth all of the edges to ensure a smooth transition between the two sections, as well as between the fillet and the tunnel wall. 


\section{Instrumentation}

During testing, pressure and temperature data were collected for the flow field, as well as position measurements and limited schlieren and oil flow visualization images.

\section{Facility Instrumentation}

The tunnel conditions during the test were recorded by instrumentation standard to the facility. The total pressure and temperature were measured in the plenum. The facility mass flow rate was measured with a venturi in the system upstream of the plenum. Two static pressures were averaged for the facility Mach number calculation. The static pressure taps were located on either side of the converging-diverging nozzle, near the nozzle exit.

\section{Pressure Data}

The bulk of the data recorded and analyzed for this effort was pressure data. Static pressures were recorded on the tunnel floor with 73 static taps on the centerline and 10 static taps located $2.5 \mathrm{~cm}$ off of the centerline on either side, as shown in Figure 10.

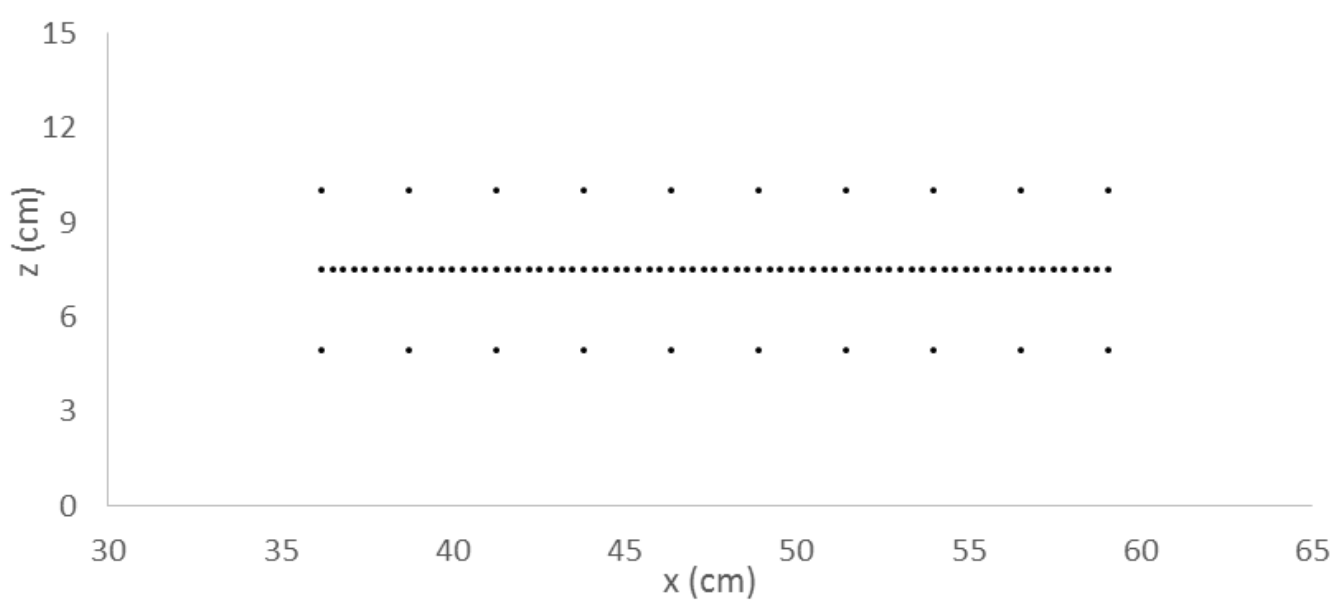

FIGURE 10. LOCATION OF STATIC PRESSURE TAPS. EACH DOT REPRESENTS A TAP LOCATION. 
A Pitot probe was mounted on the translation mechanism so that an array of total pressures could be measured downstream of the shock reflection. The probe was positioned with the probe tip at $x=55.4 \mathrm{~cm}$, between the shock reflection and the leading edge of the expansion fan from the shock generator. The primary measurement plane location can be seen as the purple line in Figure 7. The goose-necked probe was angled at 45 degrees to be able to measure into the corner. The translating probe was designed with an electric circuit that closed when the probe was in contact with the wall. The probe position was calibrated before each run using the voltage change to determine the probe touch location. Where possible, a wind-on tare was completed as well.

The distributions of points measured for the upstream plane, the no fillet case, and the largest fillet case are shown in Figure 11. The upstream measurement plane included additional boundary layer surveys along the tunnel sidewall for a total of 15 boundary layer surveys. The no fillet and fillet configurations included 12 boundary layer surveys: one in the corner along the bisector, seven z-profiles, and four y-profiles. The corner boundary-layer profile consisted of 50 points. Each of the other profiles consisted of 45 points. For the fillet configurations, the spacing for the corner surveys was compressed as needed to retain the same number of data points. The profiles were clustered with more measurements near the wall, and data points farther apart as the points approached the core flow. Additionally, 27 points scattered between the profiles were collected to smooth out contour plots created from the data. 


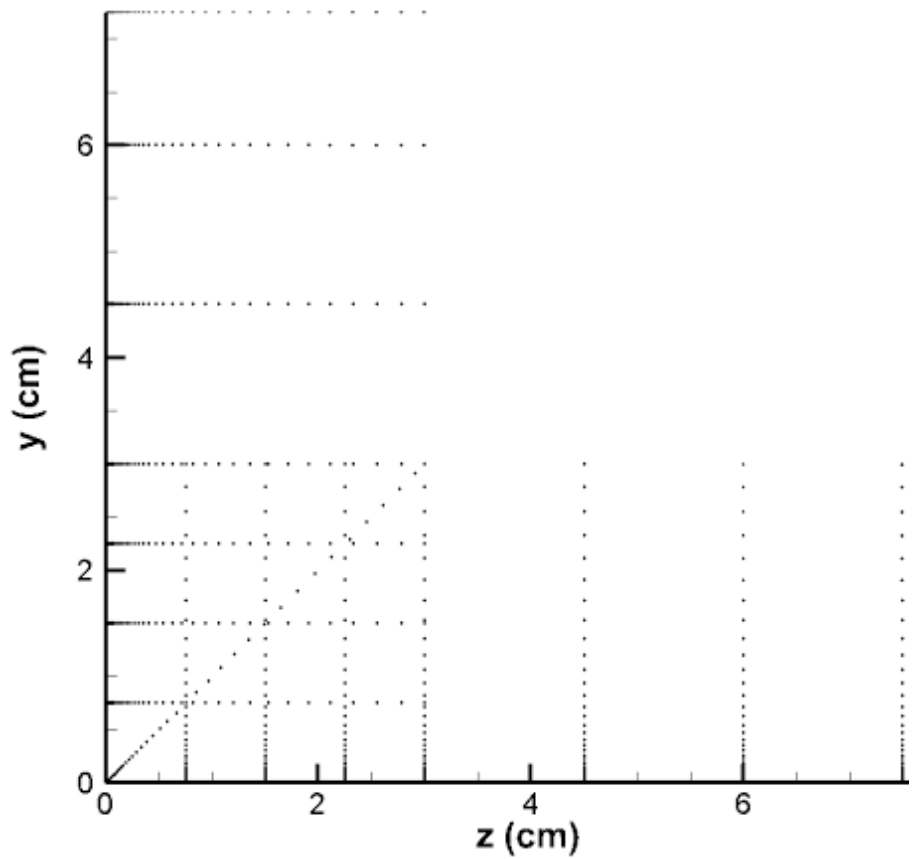

(A) Upstream Measurement PLANe

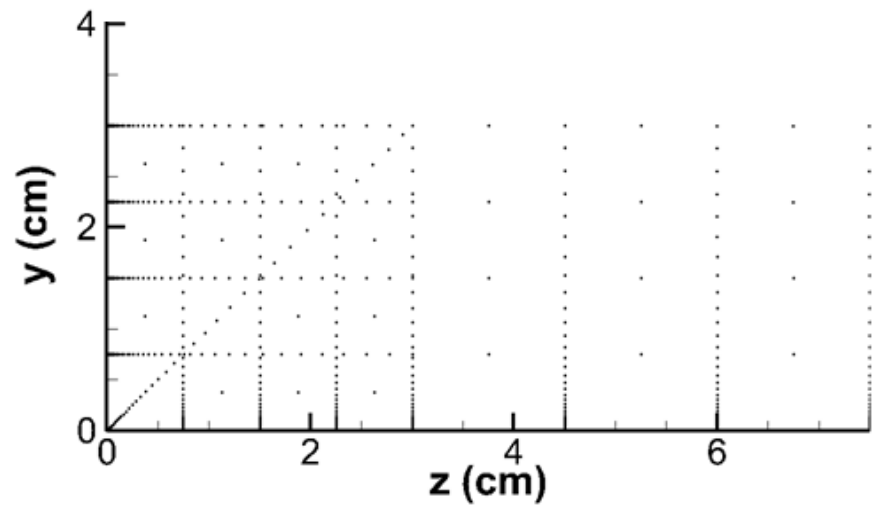

(B) No FILLET

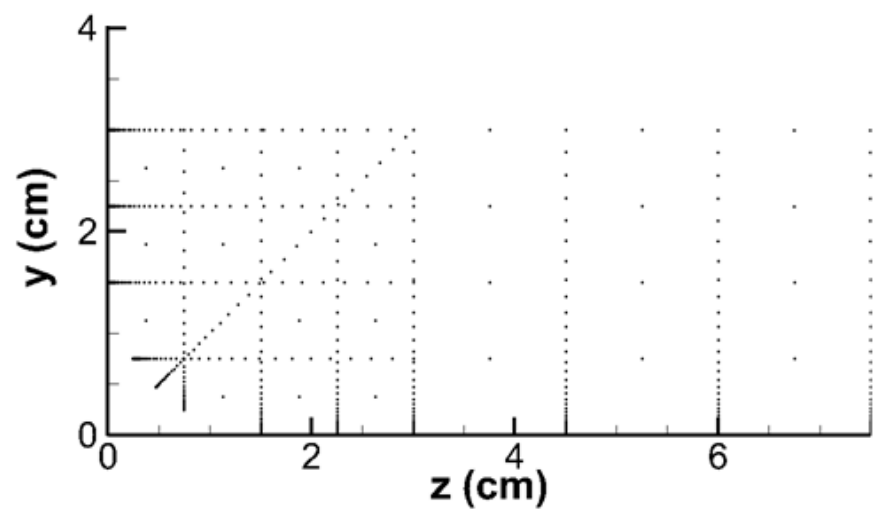

(C) LARGEST FILLET

FIGURE 11. ARRAY OF MEASURED PITOT PRESSURE LOCATIONS. 


\section{Additional Instrumentation}

The angle of the oblique shock generator was measured with a rotary encoder which attached to one of the pivot pins that extended through the plexiglass window. This encoder was calibrated daily using an inclinometer.

For a limited number of cases, schlieren images and oil flow visualization were recorded.

\section{Experimental Uncertainty}

Experimental measurements have some bias and precision errors associated with them. While we cannot know the exact magnitude of these errors, estimates can be made of the uncertainty associated with the measurements.

The $103 \mathrm{kPa}$ pressure transducers used for this study have a built in uncertainty of $0.05 \%$ of full scale. The as-recorded uncertainty, which accounts for each component in the system, increases to $0.07 \%$ of full scale, or $\pm 0.07 \mathrm{kPa}$ equivalently. The type $\mathrm{E}$ thermocouples used have an as-recorded uncertainty of $\pm 1.4 \mathrm{~K}$.

Based on a propagation of uncertainty analysis, Table 1 shows calculated values and the associated uncertainty for Mach number, static temperature, the speed of sound, and velocity for three flow conditions. These three conditions represent a typical near wall subsonic case, the supersonic boundary-layer edge case downstream of the reflected shock, and the core flow upstream of the shock from top to bottom respectively. 
TABle 1. Propagation OF UnCertainty for three floW CONDITIONS.

\begin{tabular}{|c|c|c|c|c|c|c|}
\hline \multicolumn{2}{|c|}{ Mach 0.54} & & \multirow[b]{2}{*}{ sM } & \multirow[b]{2}{*}{0.0085} & \multirow[b]{3}{*}{$K$} & \multirow[b]{2}{*}{$1.57 \%$} \\
\hline M & 0.540 & & & & & \\
\hline $\mathrm{T}_{\mathrm{s}}$ & 278.2 & K & $s T_{s}$ & 1.40 & & $0.50 \%$ \\
\hline a & 334.3 & $\mathrm{~m} / \mathrm{s}$ & sa & 0.84 & $\mathrm{~m} / \mathrm{s}$ & $0.25 \%$ \\
\hline u & 180.5 & $\mathrm{~m} / \mathrm{s}$ & su & 2.87 & $\mathrm{~m} / \mathrm{s}$ & $1.59 \%$ \\
\hline \multicolumn{2}{|c|}{ Mach 1.44} & & \multirow[b]{2}{*}{ sM } & \multirow[b]{2}{*}{0.0022} & & \multirow[b]{2}{*}{$0.15 \%$} \\
\hline M & 1.44 & & & & & \\
\hline $\mathrm{T}_{\mathrm{s}}$ & 208.4 & K & $\mathrm{sT}_{\mathrm{s}}$ & 1.00 & K & $0.48 \%$ \\
\hline$a$ & 289.4 & $\mathrm{~m} / \mathrm{s}$ & sa & 0.69 & $\mathrm{~m} / \mathrm{s}$ & $0.24 \%$ \\
\hline $\mathrm{u}$ & 416.7 & $\mathrm{~m} / \mathrm{s}$ & su & 1.18 & $\mathrm{~m} / \mathrm{s}$ & $0.28 \%$ \\
\hline \multicolumn{2}{|c|}{ Mach 2} & & \multirow[b]{2}{*}{ sM } & \multirow[b]{2}{*}{0.0052} & & \multirow[b]{2}{*}{$0.26 \%$} \\
\hline M & 1.99 & & & & & \\
\hline $\mathrm{T}_{\mathrm{s}}$ & 165.5 & K & $s T_{s}$ & 0.86 & K & $0.52 \%$ \\
\hline a & 257.8 & $\mathrm{~m} / \mathrm{s}$ & sa & 0.67 & $\mathrm{~m} / \mathrm{s}$ & $0.26 \%$ \\
\hline $\mathrm{u}$ & 513.1 & $\mathrm{~m} / \mathrm{s}$ & su & 1.89 & $\mathrm{~m} / \mathrm{s}$ & $0.37 \%$ \\
\hline
\end{tabular}

Uncertainties were also estimated for the boundary layer thickness and incompressible shape factor based on the uncertainty in the velocity. The edge velocity was held fixed while the rest of the profile was shifted first to increase all velocities along the measured profile by the appropriate uncertainty in velocity. This allowed a lower bound on the boundary layer thickness and incompressible shape factor to be calculated. Then the upper bound was found in the same way, but with all velocities along the profile decreased by the appropriate uncertainty. Error bars are presented on many of the figures based on these estimates. Based on these estimates, the maximum uncertainty 
in boundary layer thickness was $0.19 \mathrm{~cm}$, and the maximum uncertainty in incompressible shape factor was 0.02 .

\section{E. Test Cases}

A total of 11 cases were included in the final test matrix for this effort. These included an upstream measurement plane to observe the inflow, a baseline measurement downstream of the oblique shock with no fillet, eight fillet configurations, and one case with the largest fillets as well as micro-ramp vortex generators.

For the upstream profile, the probe tip was moved to $x=40.2 \mathrm{~cm}$. The measurement plane location can be seen in Figure 7. Measurements were made at each of the locations shown for the upstream measurement plane case in Figure 11. As shown in the figure, additional boundary-layer surveys were recorded for $y=4.5 \mathrm{~cm}, \mathrm{y}=6.0 \mathrm{~cm}$, and $\mathrm{y}=7.25$ $\mathrm{cm}$. The range of the probe did not reach $y=7.5 \mathrm{~cm}$. These surveys mapped one quadrant of the tunnel inflow.

The downstream baseline was measured at the same $x$-station as were the fillet configurations. Eight fillet configurations were tested while varying three geometric parameters. Four levels were tested for the fillet radius and length, and two levels were tested for the taper length. The combinations tested are listed in Table 2. Values in the table have been normalized by the boundary-layer thickness measured upstream, $\delta=1.24$ $\mathrm{cm}$.

The levels of the variables were selected to attempt to bound the problems within the confines of the available space in the test section. The smallest value of each variable was 
expected to have little effect on the flow. The largest value of the fillet radius was based on the lip of the schlieren frame that was available to support the fillet on the sidewall during formation. The largest values of length and taper were a combination which represented the farthest upstream location that could be accessed through the sidewall openings.

TABLE 2. FILLET CONFIGURATIONS.

\begin{tabular}{|c|c|c|c|}
\hline Label & $r / \delta$ & $1 / \delta$ & $t / \delta$ \\
\hline \hline $\mathrm{A}$ & 0.51 & 0 & 11.0 \\
\hline $\mathrm{B}$ & 0.51 & 22.0 & 2.75 \\
\hline $\mathrm{C}$ & 0.77 & 7.35 & 2.75 \\
\hline $\mathrm{D}$ & 0.77 & 14.7 & 11.0 \\
\hline $\mathrm{E}$ & 1.02 & 7.35 & 11.0 \\
\hline $\mathrm{F}$ & 1.02 & 14.7 & 2.75 \\
\hline $\mathrm{G}$ & 1.28 & 0 & 2.75 \\
\hline $\mathrm{H}$ & 1.28 & 22.0 & 11.0 \\
\hline
\end{tabular}

One configuration was run with micro-ramp vortex generators near the centerline combined with the largest fillet configuration $(r / \delta=1.28,1 / \delta=22.0, t / \delta=11.0)$. The microramp geometry is shown in Figure 12. For this test, the micro-ramps tested had a height $h=5 \mathrm{~mm}$, chord length $c=24 \mathrm{~mm}$, and a vertex half-angle $\alpha=24$ degrees. Three microramps were installed, and the vertex of the middle micro-ramp was on the tunnel centerline. The spacing between the micro-ramps was $s=25 \mathrm{~mm}$. The micro-ramp centerline was located at $x=38 \mathrm{~cm}$. The micro-ramps tested were the same as those studied previously in this facility [44, 45]. 


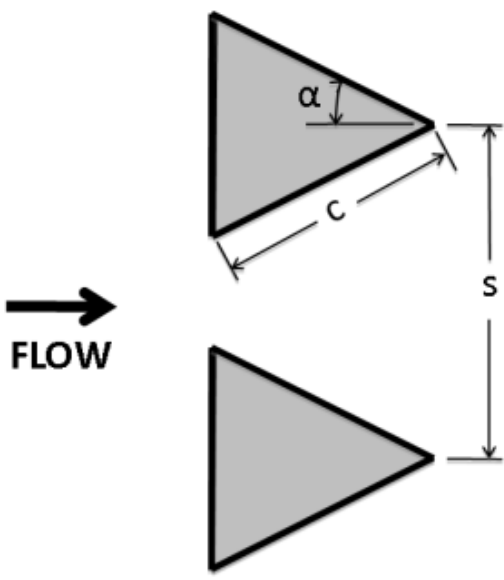

(A) TOP VIEW

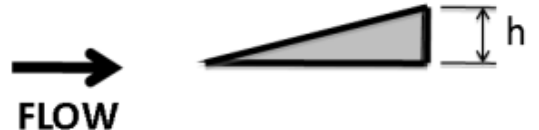

(B) SIDE VIEW

FIGURE 12. MICRO-RAMP GEOMETRY PARAMETERS. 


\section{Analysis Methodology}

\section{A. Data Averaging}

An approach to data averaging was used which attempted to minimize the tunnel run time while maintaining data accuracy. When flow conditions change as pressure measurements are made, care must be taken to allow time for the pressure change to equilibrate in the pressure line and be registered by the transducer. For most of the measurements in this test entry, changes between data points were small. The tunnel stayed on the same condition for approximately three hours as the Pitot probe translated throughout the survey plane. The Pitot probe, however could see large changes in pressure between data points depending on the position in the profile.

Estimates were made for the settling time in the pressure line that would be required to take steady state measurements. For the Pitot probe, these times ranged from a few seconds to nearly ten seconds for a few of the points. Because most points had predicted settling times of less than five seconds, that was the time chosen as the pause period between data points.

Adjustments were made during data analysis for cases that required longer settling times. During the test, data were recorded once per second for ten seconds at each probe location. For all data other than the Pitot probe pressure, all ten scans were averaged.

Based on the pretest approximation of settling time and the five second pause built into the survey, it was expected that the final five seconds measured would be steady state, settled data. The mean of these last five scans was compared to the median for 
each data point to check for outliers. Outliers were identified for only 15 cases during the data analysis and in those cases, a single scan was dropped from the five.

For each data point the final five scans of data were averaged. Then the previous points were included one at a time into the average with a check to ensure that including the point did not change the mean by more than $0.1 \%$. For one typical case, this resulted in $66 \%$ of the points in the profile using all ten scans in the final average, and only $6 \%$ using four or five scans.

\section{B. Identifying the Wall Location}

Because a translating probe mechanism was used which had some backlash inherent in the position measurement, the measured pressure data were used to determine the actual wall location for each profile. The process for this correction started with shifting the profile location such that the first point was zero. This was already the case for profiles that were not affected by the fillet.

The minimum Pitot pressure in the profile was identified. Then, the first five points with a Pitot pressure at least one percent higher than the minimum were used to fit a second order polynomial. The position where that polynomial intersected the minimum Pitot pressure became the first estimate of the true wall location.

If the flow was separated, the wall location calculated based on the pressure as described would be incorrect because the Pitot pressure is approximately constant in the separation region. For profile locations where the probe touches the steel tunnel at the wall we can check the measured touch probe voltage at the estimated wall location as an 
additional source of information. If the voltage is sufficiently depressed at the estimated wall position then the estimate is accepted as correct.

The baseline voltage for the touch probe system is $3600 \mathrm{mV}$. Based on examination of profiles from this and other data sets, the voltage was in the range of $2000 \mathrm{mV}$ to 2700 $\mathrm{mV}$ when the probe left the wall. The difference between these two values is attributed to small vibrations of the probe causing occasional contact. While this check was not available for every profile location, because of the careful alignment of the tunnel before the test, the position of the probe leaving the wall varied by only approximately $0.02 \mathrm{~cm}$ across the span. If the voltage was high at the wall location estimated based on pressure, a combination of the probe voltage and the locations of other wall positions within the same data set were used to determine the actual wall location.

The profiles were then adjusted to undo the initial position offset, shift the profile based on the calculated wall locations, and account for the probe diameter. The result of this adjustment was to move the measured wall point to a position equal to half the probe diameter. The redundant wall points were removed from all the measurements.

Additionally, the static pressure was compared to the minimum Pitot pressure. For some cases, due to measurement errors, the static pressure was slightly higher than the minimum Pitot pressure, though this was always within the experimental uncertainty. For these cases, the static pressure was adjusted to be equal to the minimum Pitot pressure. 


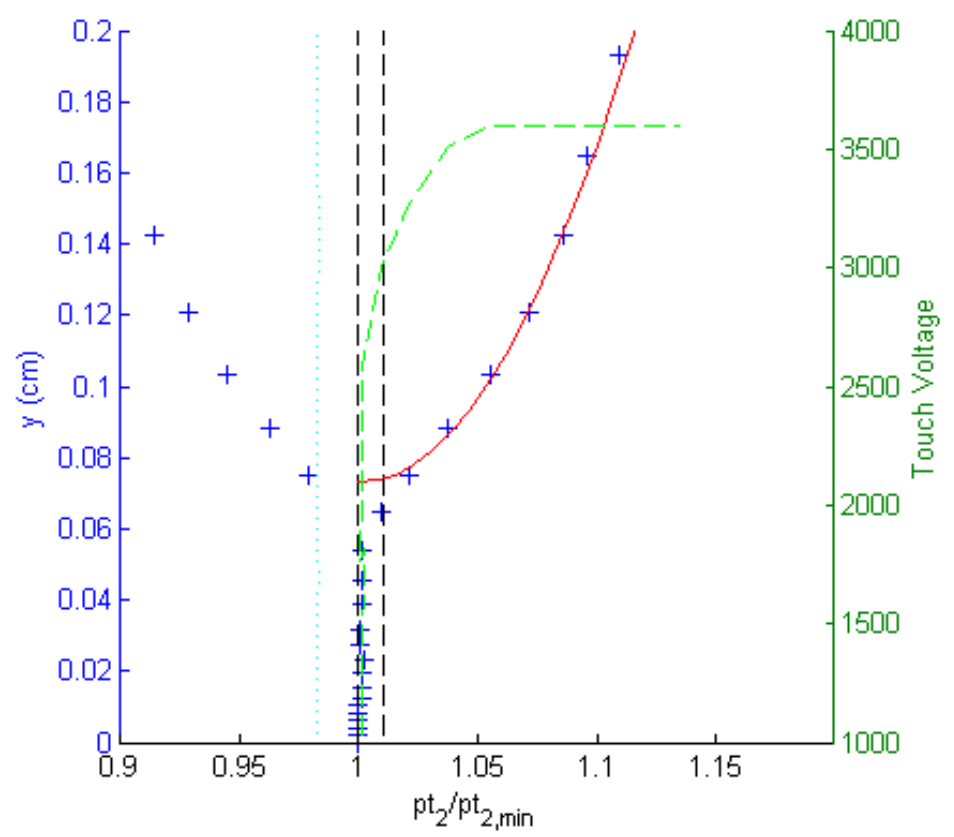

(A) BEFORE CORRECTION

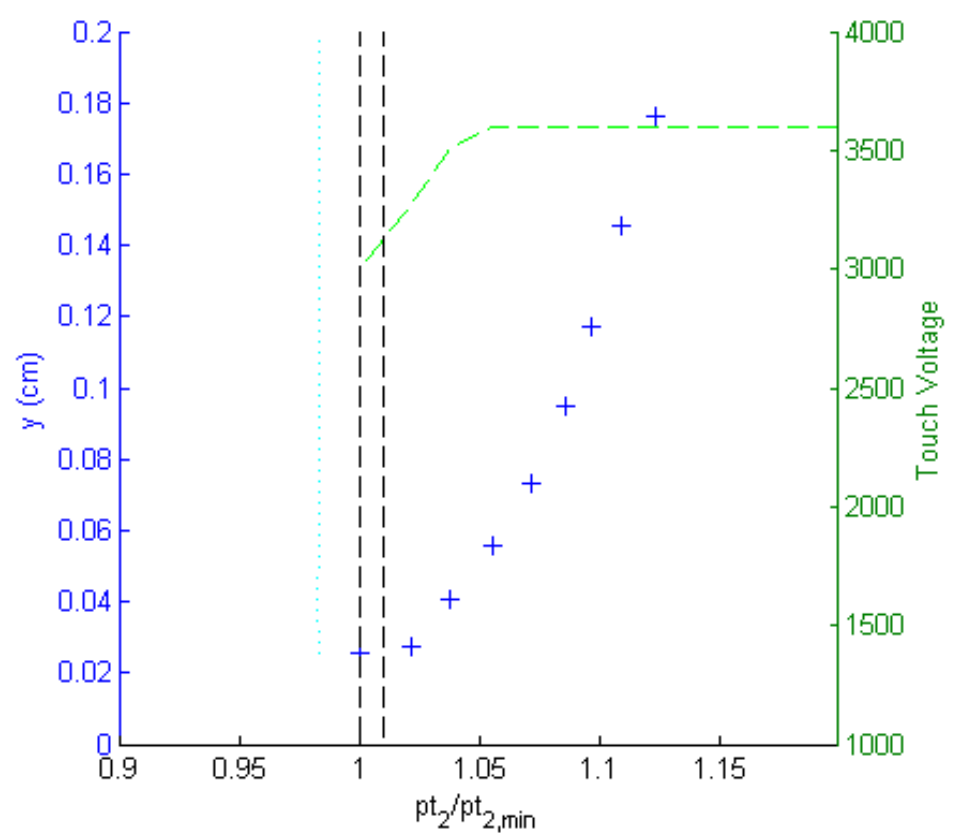

(B) AFTER CORRECTION

FiguRE 13. SAMPLE OF THE PLOT USED TO ESTIMATE THE WALL TOUCH LOCATION. 
An example of the plot generated to examine the wall adjustment is shown in Figure 13. Part $\mathrm{A}$ of the figure shows the data before the correction. The minimum total pressure and a $1 \%$ increase over that level are shown by the dashed black vertical lines. The measured Pitot pressures are shown as blue crosses, as are five reflected points which were used in the second order curve fit, shown in red. The light blue dotted line shows the static pressure. All of these curves use the primary y-axis. The secondary y-axis is used to show the touch probe voltage in green.

In the example shown the prediction based on the pressures agrees with the rise in touch probe voltage and so the calculated wall value is accepted. The resulting adjusted Pitot pressure profile is shown in part B of the figure.

\section{Preprocessing}

Before boundary-layer parameters were calculated, data points were corrected for variations in the inflow conditions, and average reference conditions were computed. Additionally, interpolation was done to calculate the local static pressure.

Corrections for plenum variation were applied for the nozzle statics, wall statics, and the probe pressure. The average plenum pressure across the profile was calculated. Then, each of the other measured pressures was multiplied by the ratio of the average plenum pressure to the associated individually recorded plenum pressure.

For each profile, tunnel conditions were averaged across all of the measurements to determine the reference conditions. This was done for the tunnel freestream total 
temperature and pressure, the nozzle static pressure, and the freestream Mach number and velocity.

\section{Calculation of Properties at the Measurement Plane}

Because the measurement plane was located between two static taps, the pressures were interpolated to determine the static pressure at the measurement station. The Pitot to static pressure ratio was used to determine the Mach number. For subsonic flow the relation is given by Equation (1).

$$
\frac{p_{t, 2}}{p_{1}}=\left[1+\frac{(\gamma-1) M^{2}}{2}\right]^{\frac{\gamma}{\gamma-1}}
$$

For supersonic flow, a normal shock develops in front of the Pitot tube. For this condition, the Rayleigh-Pitot tube formula, shown in Equation (2) is used to calculate the Mach number. Because the Rayleigh Pitot tube formula has no closed form solution for Mach number, an iterative bisection method was used.

$$
\frac{p_{t, 2}}{p_{1}}=\left[\frac{(\gamma+1) M_{1}^{2}}{2}\right]^{\frac{\gamma}{\gamma-1}}\left[\frac{\gamma+1}{2 \gamma M_{1}^{2}-(\gamma-1)}\right]^{\frac{1}{\gamma-1}}
$$

Based on the calculated Mach number, the total pressure for the supersonic data points is determined from Equation (1). 


\section{E. Edge Conditions}

To determine the boundary-layer edge conditions, a series of points were averaged based on the slope of the Pitot pressure profile. To determine which points to average, the edge Pitot pressure was set initially to the maximum Pitot pressure. Then, a monotonic derivative curve fit was used to fit the function $\left(p_{t, 2}-p_{1}\right) /\left(p_{t, 2 e}-p_{1}\right)$ versus the wall distance. The first point to average to determine the edge conditions was selected where the first derivative based on the curve fit was less than 0.1 and the wall distance was greater than $0.5 \mathrm{~cm}$. Once that location was determined, the last point to use in the average was determined by the last data point of the profile or 1.25 times the wall distance of the first edge point, whichever came first.

Assuming a total temperature equal to the tunnel total temperature, the static temperature and velocity were calculated using equations (3) and (4) respectively.

$$
\begin{gathered}
T_{s}=\frac{T_{t}}{\left(1+\frac{\gamma-1}{2} M^{2}\right)} \\
u=M \sqrt{\gamma R T_{s}}
\end{gathered}
$$

\section{F. Boundary-Layer Parameters}

At this stage, boundary-layer parameters could be calculated, beginning with the boundary-layer thickness, defined as the distance where the velocity reached $99 \%$ of the edge velocity. Interpolation was used to determine the boundary-layer thickness. 
Integral boundary-layer parameters were calculated using a modified Simpsons Rule method. The equations for the incompressible integral parameters, displacement thickness and momentum thickness, are shown in Equations (5) and (6).

$$
\begin{gathered}
\delta_{i}^{*}=\int_{0}^{\infty}\left(1-u / u_{e}\right) \\
\theta_{i}=\int_{0}^{\infty} u / u_{e}\left(1-u / u_{e}\right)
\end{gathered}
$$

The incompressible form of the integral parameters is used in order to compute the incompressible shape factor, which is used instead of the compressible form even in compressible flow because it is independent of Mach number. A flat plate turbulent boundary layer has an incompressible shape factor of approximately 1.3 at all Mach numbers. The definition of the shape factor is shown in Equation (7).

$$
H_{i}=\frac{\delta_{i}^{*}}{\theta_{i}}
$$




\section{Results}

\section{A. Upstream Flow field}

A pressure survey was taken at a plane upstream of the interaction region in order to understand the inflow conditions and confirm that the inflow boundary layer was turbulent. A measurement location of $x=40.2 \mathrm{~cm}$ was selected. Additional profiles were measured along the tunnel sidewall to survey one quadrant of the flow field.

The Mach number contours resulting from this upstream survey are shown in Figure 14, while Figure 15 shows lines of isovelocity normalized by the core velocity with the values labeled along the lines. The Mach number contours show a freestream Mach number near 2.0 as expected. Calculated edge Mach numbers range from 1.91 to 2.00 . A subsonic region can be seen in the corner with lower Mach numbers than are visible elsewhere along the wall. The subsonic layer measured for the corner profile was nearly twice as thick as that for any other profile.

This region can also be observed in the isovelocity contours. The lowest measured normalized velocity away from the corner was 0.51 . The lowest measured normalized velocity for the corner profile was 0.35 .

Additionally, both plots show a flow pattern typical for rectangular nozzles with contouring on two walls. On the floor of the tunnel where the nozzle was contoured, the boundary layer was relatively uniform across the span. On the sidewall where the nozzle was flat, a bowing of the contours can be seen with the boundary layer thinner near the corner and thicker near the center of the span. 


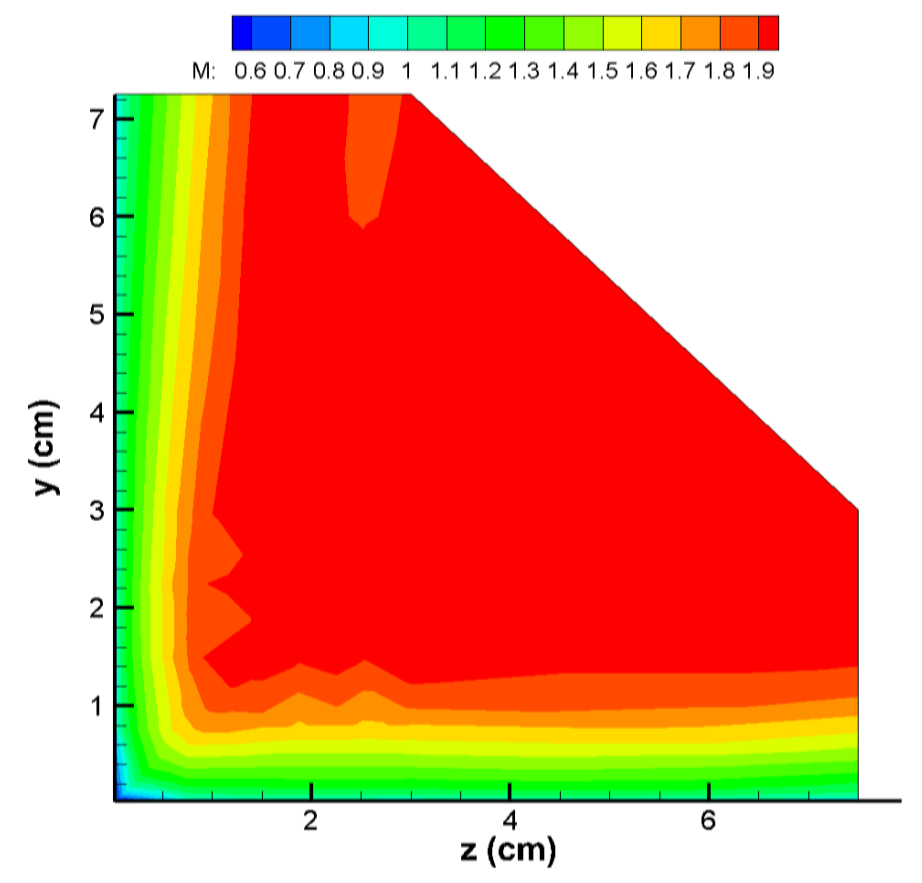

FIGURE 14. MACH CONTOURS FOR THE UPSTREAM PLANE MEASURED AT X $=40.2 \mathrm{CM}$.

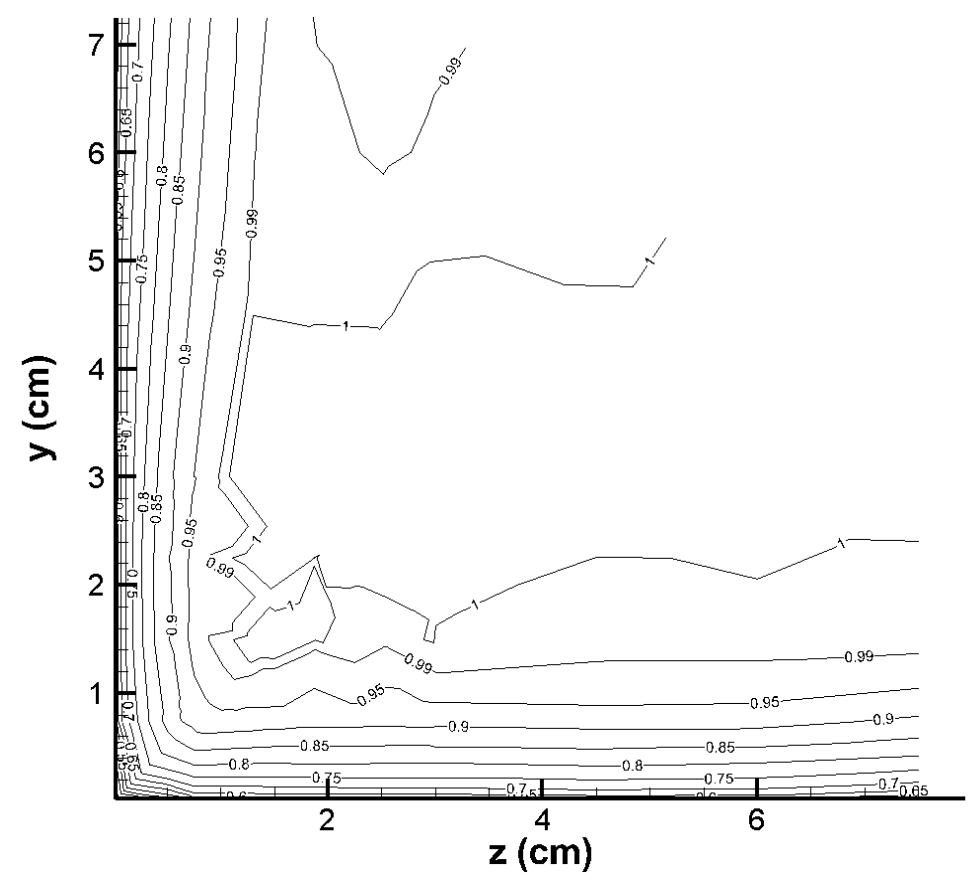

FIGURE 15. ISOVELOCITY CONTOURS FOR THE UPSTREAM PLANE MEASURED AT X $=40.2 \mathrm{CM}$. 
The boundary-layer thickness for each profile along the sidewall and the floor is shown in Figure 16. The abscissa of the plot shows positions on both the sidewall (left) and floor (right). The negative values are the locations of the y-profiles on the sidewall, whereas the positive values are the locations of the z-profiles on the floor. Zero is marked as a dashed line to indicate the location of the corner. The shaded area in the figure represents the boundary layer region. Boundary layer profiles measured within the shaded region are embedded within the boundary layer of the adjacent wall.

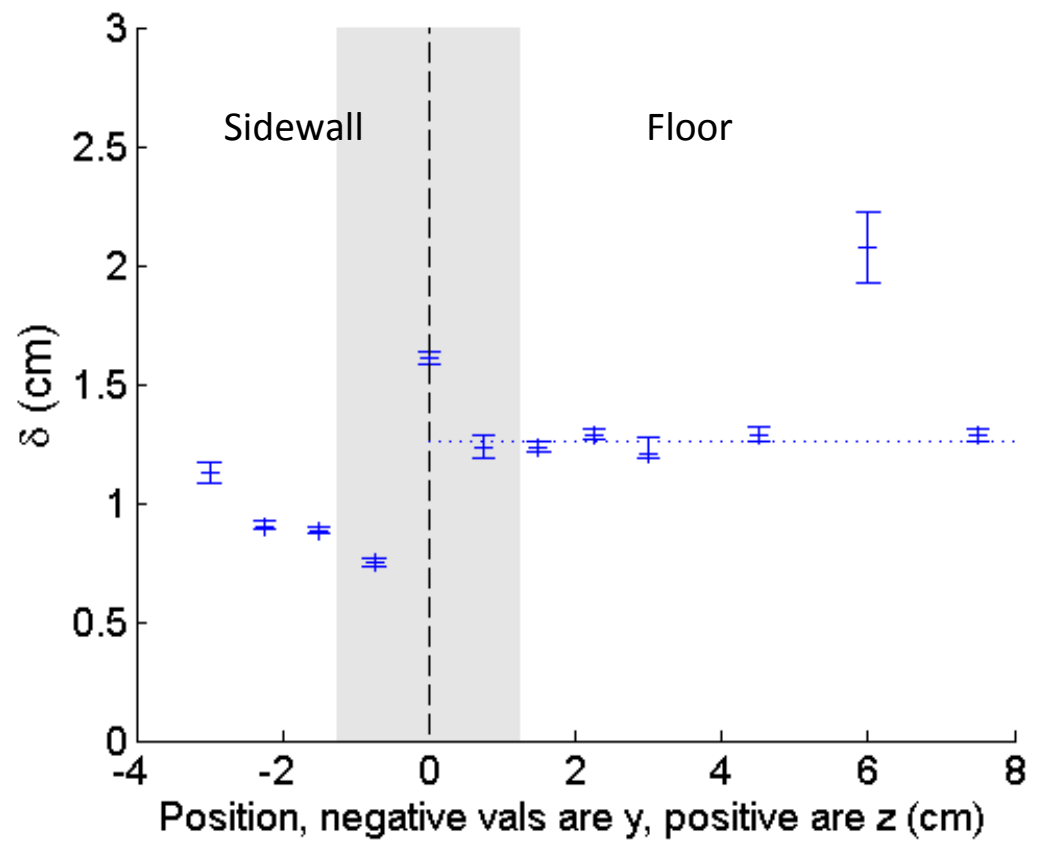

FIGURE 16. BOUNDARY-LAYER THICKNESS AT EACH PROFILE LOCATION FOR THE UPSTREAM CASE ( $X=$ $40.2 \mathrm{CM}$ ). DOTTED LINE INDICATES MEAN VALUE ALONG THE FLOOR.

The slight asymmetry about the corner bisector is likely due to the non-uniform expansion along the nozzle sidewalls $(z=0)$ where viscous effects retard the expansion in the near-wall region. The outlier for the profile at $z=6 \mathrm{~cm}$ was due to a boundary-layer 
profile that had some slope to it even in the core region. Removing that point, the average boundary-layer thickness along the floor was $1.24 \mathrm{~cm}$, which was used to normalize distances through the remainder of these results.

A similar plot can be seen in Figure 17 showing the incompressible shape factor for each profile. The shape factor was quite uniform throughout the flow field, and the measured values averaging 1.37 are consistent with a fully turbulent flow field. The corner profile had a higher shape factor, with a value of 1.58 .

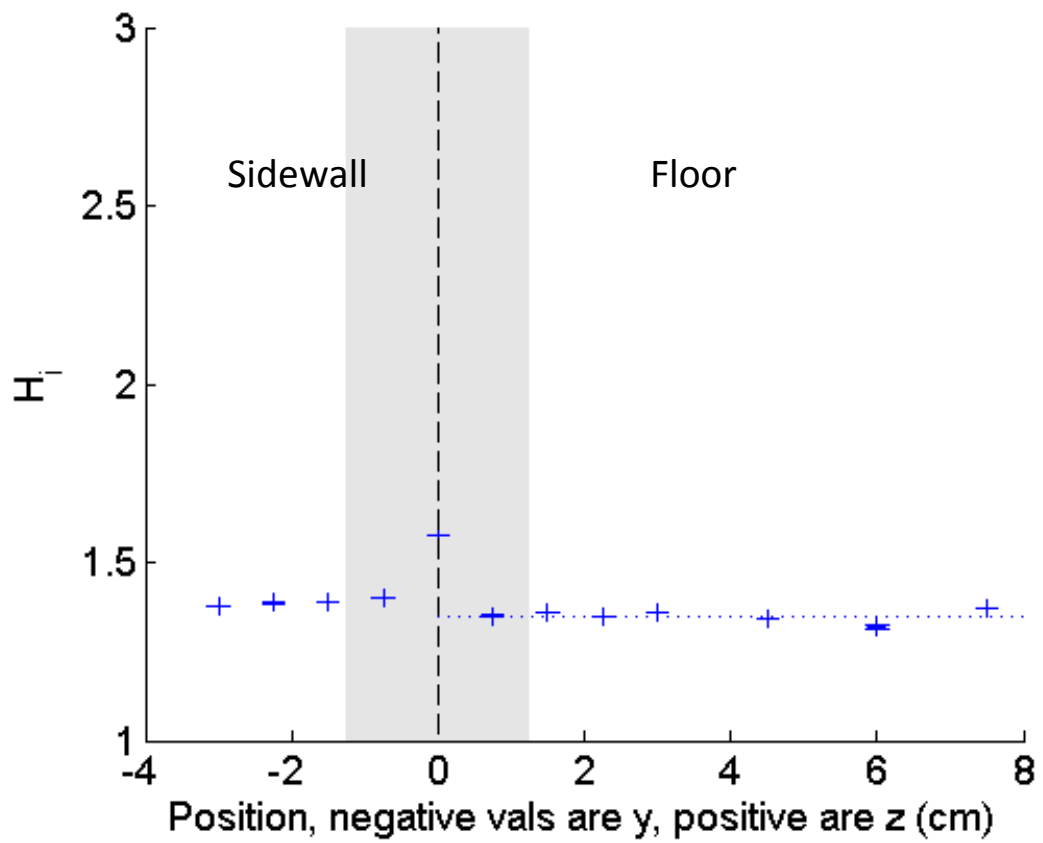

FIGURE 17. INCOMPRESSIBLE SHAPE FACTOR AT EACH PROFILE LOCATION FOR THE UPSTREAM CASE. DOTTED LINE INDICATED MEAN VALUE ALONG THE FLOOR.

\section{B. Baseline}

A survey was completed for a baseline configuration at the primary measurement plane, $x=55.4 \mathrm{~cm}$, to understand the effect of the oblique shock interaction on the corner 
flow without fillets. Photographs of oil flow visualization and schlieren are shown in Figure 18. The predicted inviscid shock impingement location is shown in the figure as a solid white line. The extent of the interaction region is shown by the dashed white lines. Multiple lines are shown for the interaction extent because the range is different in the corner compared to the centerline. The window frame interferes with the field of view for the schlieren near the wall. The x-axis lies along the tunnel wall location, so the lines tracking the shock wave angle intersect to show the location and extent of the interaction region along the tunnel floor.

It can be seen that the interaction region was upstream of the calculated inviscid shock location. This was due to viscous effects on the oblique shock generator plate as well as the tunnel floor. The formation of a boundary layer on the oblique shock generator plate effectively increased the shock generator incidence angle, leading to a slightly steeper shock angle. The impinging interaction on the tunnel floor created a separation region which distributed the interaction. 

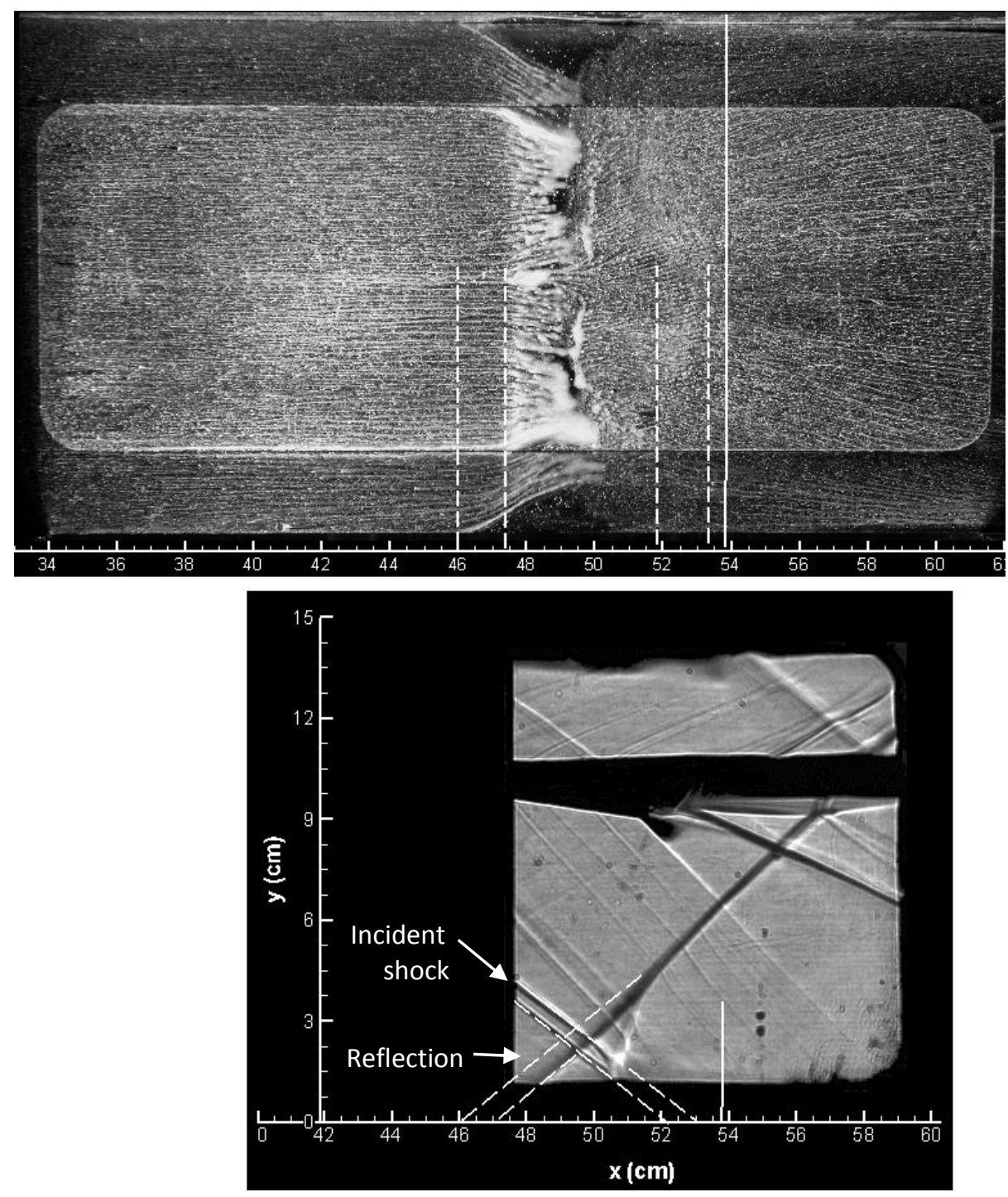

FIGURE 18. OIL FLOW VISUALIZATION (AT TOP) AND SCHLIEREN IMAGE (AT BOTTOM) FOR THE BASELINE CONFIGURATION, MACH 2.0, 8.5 ${ }^{\circ}$ SHOCK-INCIDENCE ANGLE.

Looking at the oil flow, the interaction region extended farther upstream in the corners. The upstream edge of the region across the span was straight. The downstream edge of the interaction region was curved, and the farthest effects downstream were 
seen at the centerline. Though the interaction was clearly three-dimensional, the flow field indicated by the oil flow was symmetric about the centerline.

The features in the oil flow can be correlated with the features in the schlieren image. Because the schlieren integrates the effects across the tunnel span, this threedimensional interaction is seen as a splitting of the shock and reflection in the schlieren image. The elements of the shock and reflection visible upstream correspond to the effects in the corner region, and the elements visible downstream correspond to the effects in the central region of the tunnel. It can be seen that the extent of the interaction region agrees well between the schlieren and oil flow for both the corner and centerline.

The oil flow image is repeated in Figure 19 with the shape of the interaction region indicated by an overlay. The region is compared to a computational solution generated by Benek et al. [4] in a study looking at the effect of wind tunnel width on an oblique shock interaction. The computational streamlines along the floor are shown for the computational conditions that most closely match the present experiment. In the computational study, the width to height ratio was 1.0, with a thick boundary layer entering the interaction region. While the Mach number and shock incidence angle were different (Mach 2.9, incidence angle of 13 degrees for the computational study), the results line up nicely and provide a clearer picture of what may be happening in the interaction region. 


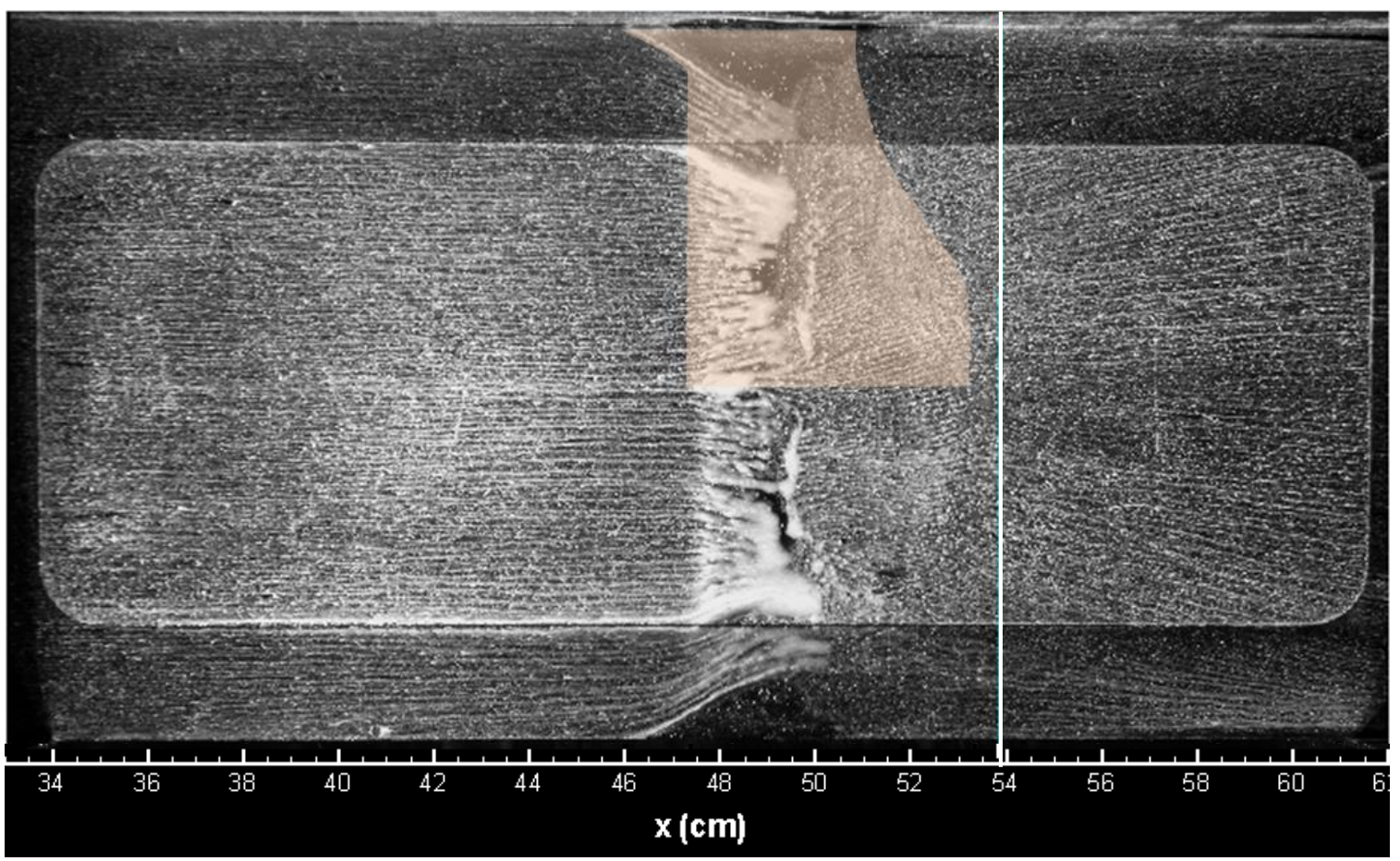

(A) MACH 2.0, 8.5 ${ }^{\circ}$ SHOCK-INCIDENCE ANGLE

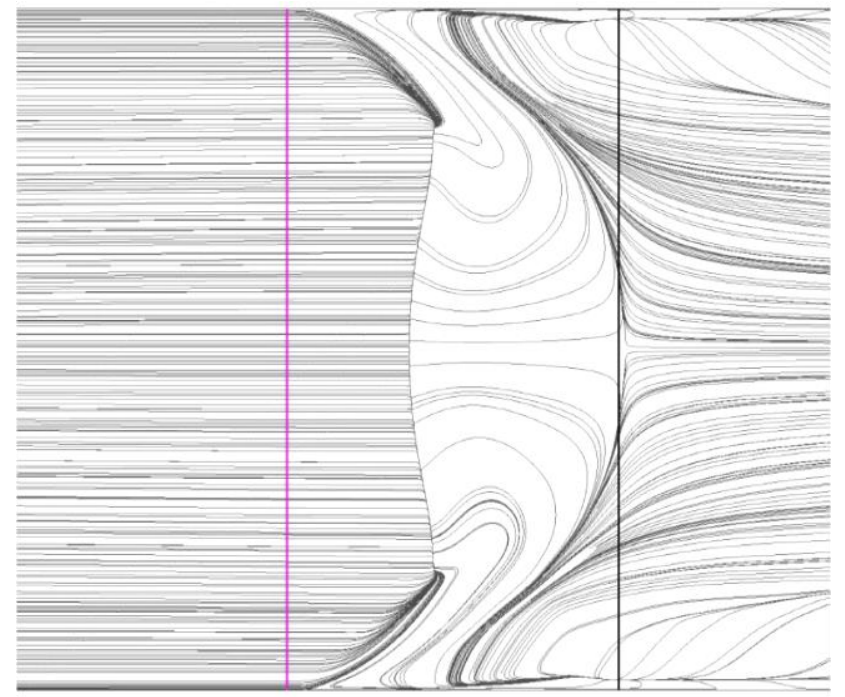

(B) MACH 2.9, $13^{\circ}$ SHOCK-INCIDENCE ANGLE

FIGURE 19. COMPARISON OF OIL FLOW VISUALIZATION TO COMPUTATIONAL RESULTS FOR A SIMILAR CONFIGURATION BY BENEK ET AL. [4] 
The extent of the pressure rise in the static pressure profile along the tunnel centerline, Figure 20, agrees well with the interaction region from the oil flow and schlieren. Ten percent of the total rise in static pressure had occurred by $x=18.4 \mathrm{~cm}$. Ninety percent of the total rise in static pressure had occurred by $x=20.8 \mathrm{~cm}$.

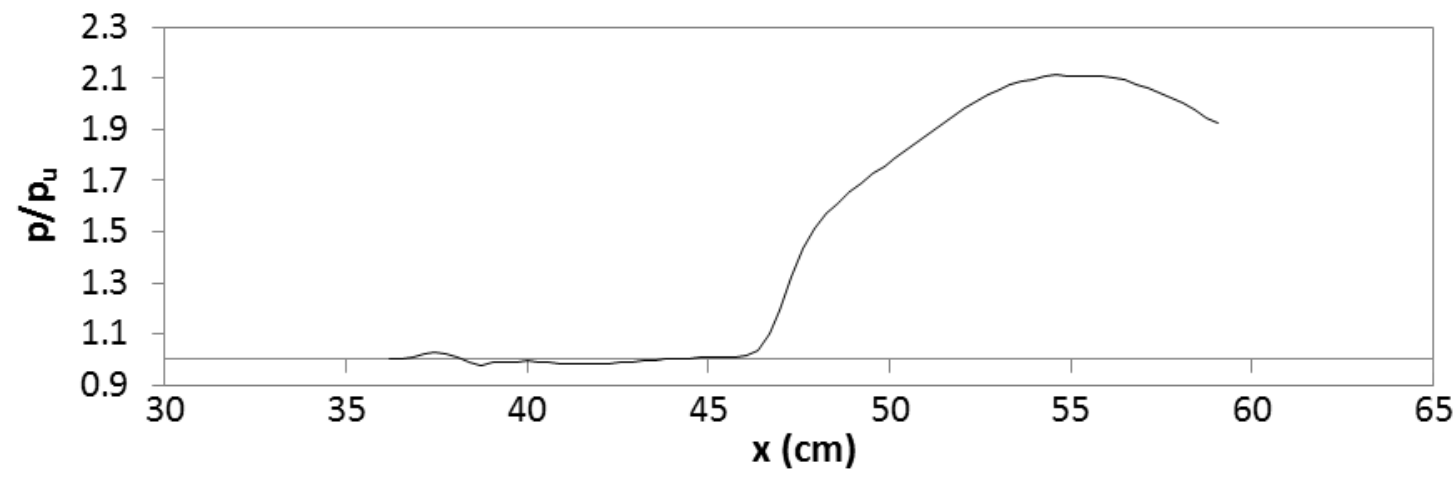

FiguRE 20. STATIC PRESSURE DISTRIBUTION ON THE TUNNEL CENTERLINE FOR THE BASELINE CONFIGURATION.

The Mach number contours and isovelocity lines resulting from the pressure survey are shown in Figure 21 and Figure 22 respectively. The average edge Mach number downstream of the shock was Mach 1.44, compared to a calculated Mach number of 1.38 downstream of a reflected shock at Mach 2.0 with 8.5 degree incidence angle. While the velocity was lowest in the corner region, at the measurement plane no separation was observed. 


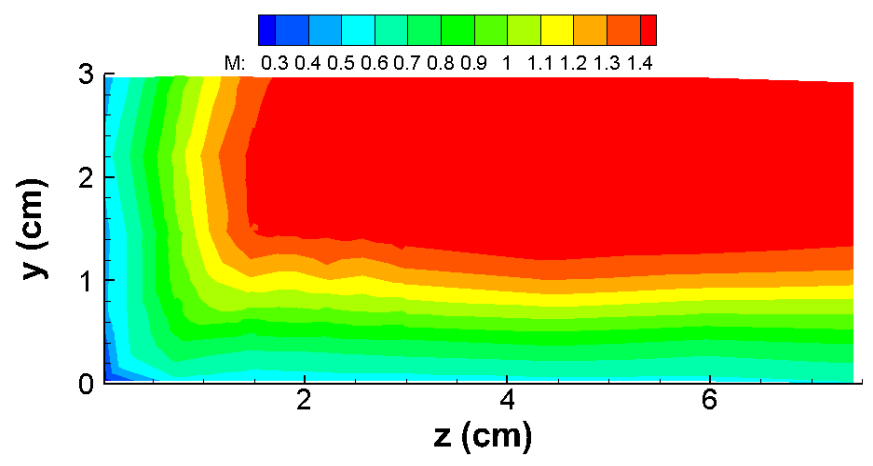

FiguRE 21. MACH NUMBER CONTOURS FOR THE BASELINE CASE.

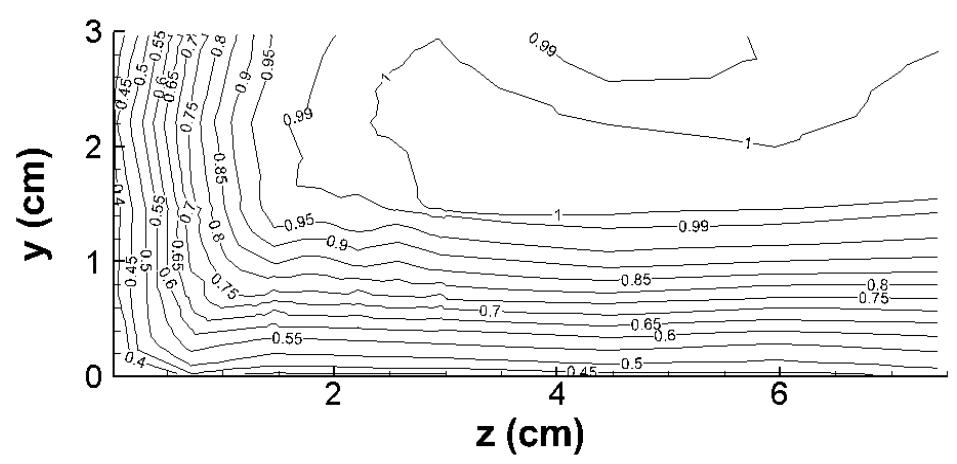

FIGURE 22. ISOVELOCITY CONTOURS FOR THE BASELINE CASE.

The boundary-layer thickness and incompressible shape factor for each profile are shown in Figure 23 and Figure 24. Again, the shaded area in the figures represents the boundary layer region. Boundary layer profiles measured within the shaded region are embedded within the boundary layer of the adjacent wall. The shock interaction increased the average boundary-layer thickness along the tunnel floor to $1.42 \mathrm{~cm}$ and the mean incompressible shape factor to 1.65 . In the corner the boundary-layer thickness increased from $1.61 \mathrm{~cm}$ before the shock to $2.33 \mathrm{~cm}$ downstream, and the incompressible shape factor increased from 1.58 to 1.89 . 


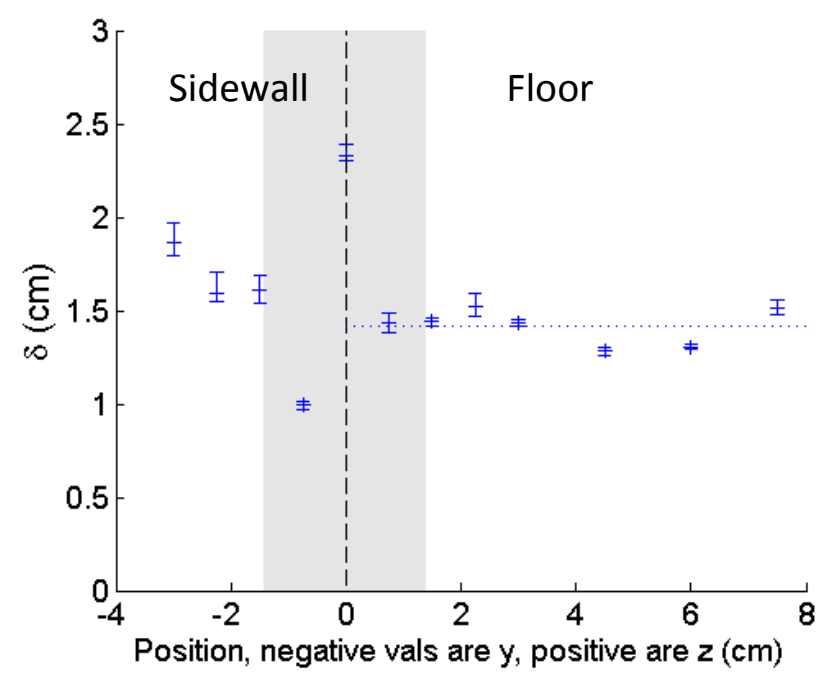

FIGURE 23. BOUNDARY-LAYER THICKNESS AT EACH PROFILE LOCATION FOR THE BASELINE CASE. DOTTED LINE INDICATES MEAN VALUE ALONG THE FLOOR.

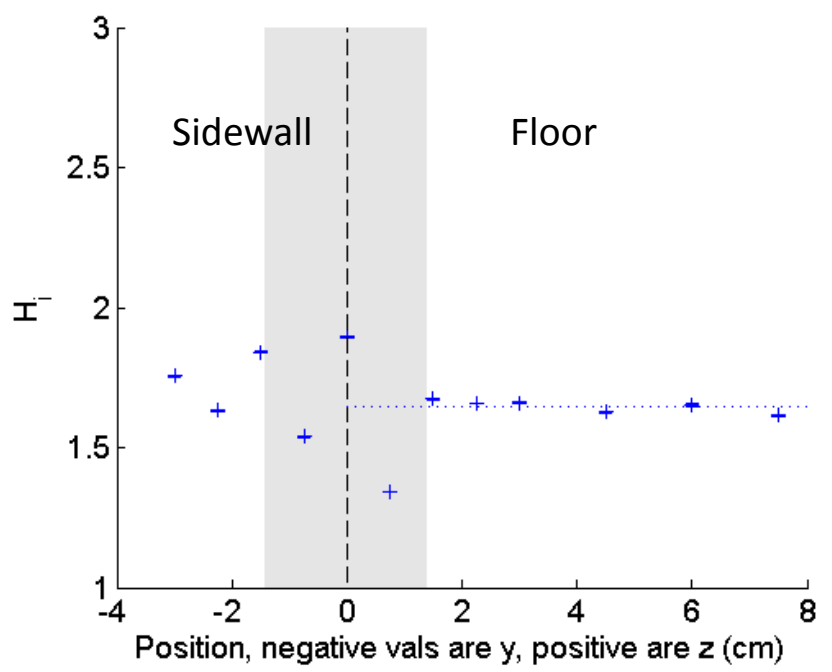

FIGURE 24. INCOMPRESSIBLE SHAPE FACTOR AT EACH PROFILE LOCATION FOR THE BASELINE CASE. DOTTED LINE INDICATES MEAN VALUE ALONG THE FLOOR.

\section{Fillet Test Matrix}

Pitot pressure surveys for each of the eight fillet configurations were analyzed to calculate the velocity field downstream of the oblique shock at $x=55.4 \mathrm{~cm}$. The lines of 
isovelocity for each of the cases are shown in Figure 25 arranged from smallest fillet radius to largest.

Compared to the baseline case from Figure 22 it can be seen that along the corner bisector, the isovelocity lines are spaced more closely for the fillet configurations, indicating a steeper velocity gradient near the wall. The lines also generally slant upward along the tunnel floor from the corner toward the centerline. For the smaller two radii, the shorter fillet length, I, from each pair has a steeper slope, suggesting a shorter length resulted in a more distorted boundary layer at the tunnel floor centerline. For the two larger radii, less difference is seen at the centerline as the length was changed.

Compressing the data from the contour plots into boundary-layer thickness at each profile location, the effects of the fillet configurations can also be seen in Figure 26. A similar trend can be seen across the cases. Starting on the sidewall the boundary-layer thickness decreased approaching the corner. Because the boundary-layer profiles measured at $0.75 \mathrm{~cm}$ and $1.5 \mathrm{~cm}$ on each wall were within the boundary layer of the other wall, those data points were not included on the plot. Moving along the tunnel floor toward the centerline, the boundary-layer thickness gradually increased.

In some cases, such as $r / \delta=1.28, I / \delta=22.0, t / \delta=11.0$ seen in part H of Figure 26 , there was a peak in the boundary-layer thickness for the profile measured at $z=2.25 \mathrm{~cm}$. Looking at the corresponding contours in part $\mathrm{H}$ of Figure 25 , this can be seen as an associated bulging of the isovels in this region, indicative of a counter-clockwise rotating streamwise vortex. 


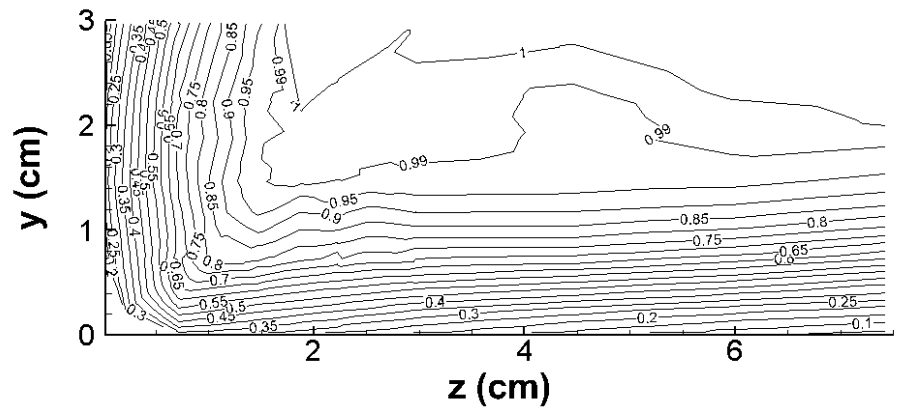

(A) $r / \delta=0.51, I / \delta=0, t / \delta=11.0$

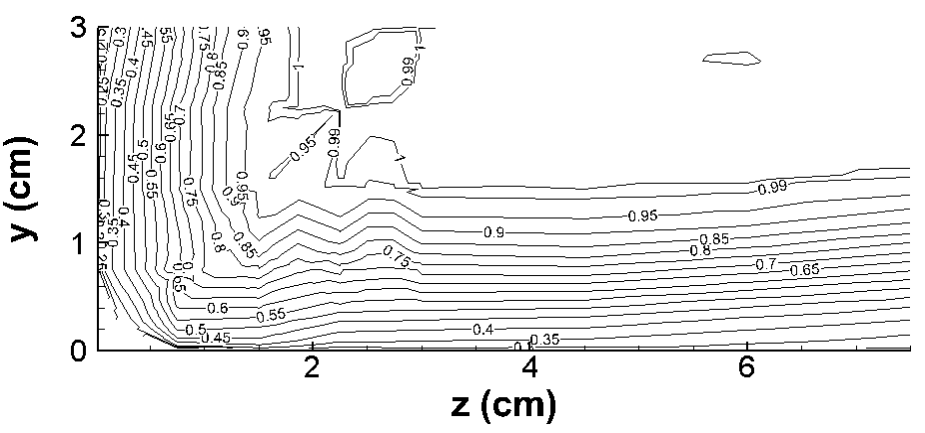

(B) $r / \delta=0.51, I / \delta=22.0, t / \delta=2.75$

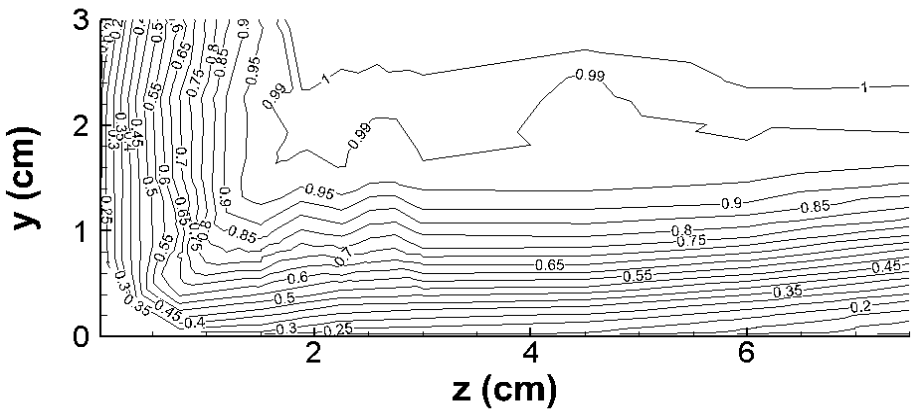

(c) $r / \delta=0.77,1 / \delta=7.35, t / \delta=2.75$

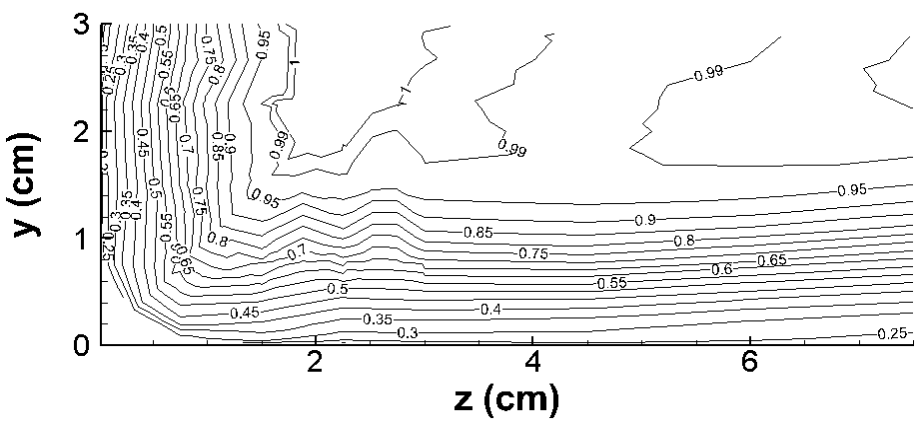

(D) $r / \delta=0.77, I / \delta=14.7, t / \delta=11.0$

FIGURE 25. NORMALIZED ISOVELOCITY CONTOURS FOR THE FILLET CONFIGURATIONS. 


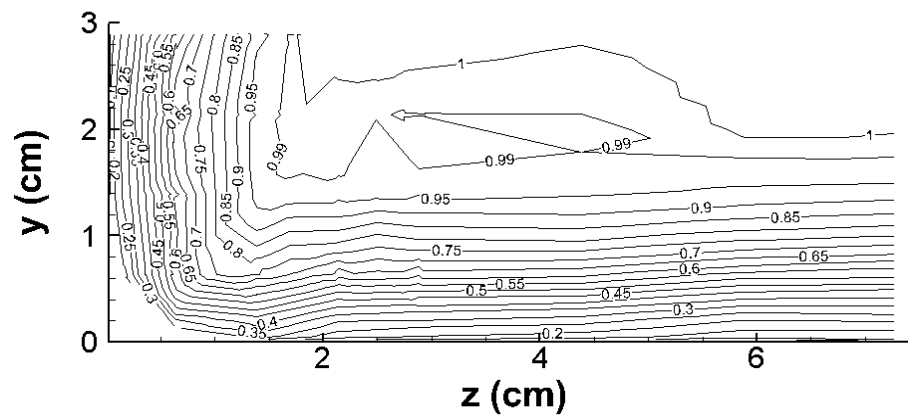

(E) $r / \delta=1.02,1 / \delta=7.35, t / \delta=11.0$

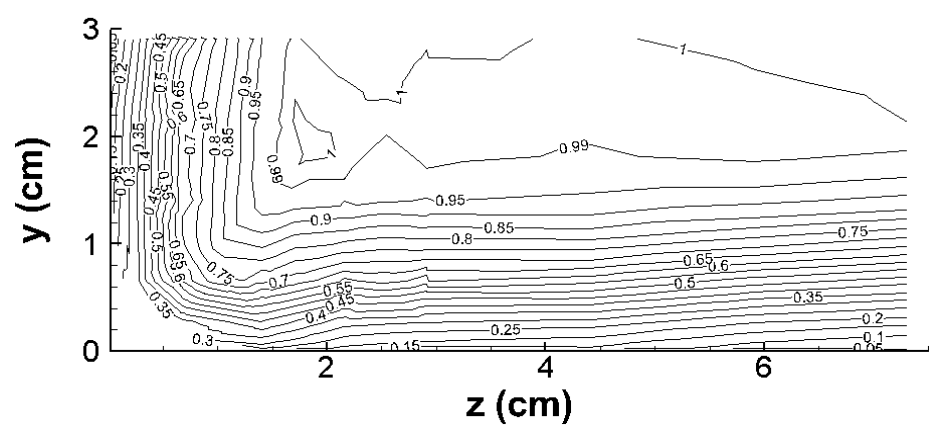

(F) $r / \delta=1.02, I / \delta=14.7, t / \delta=2.75$

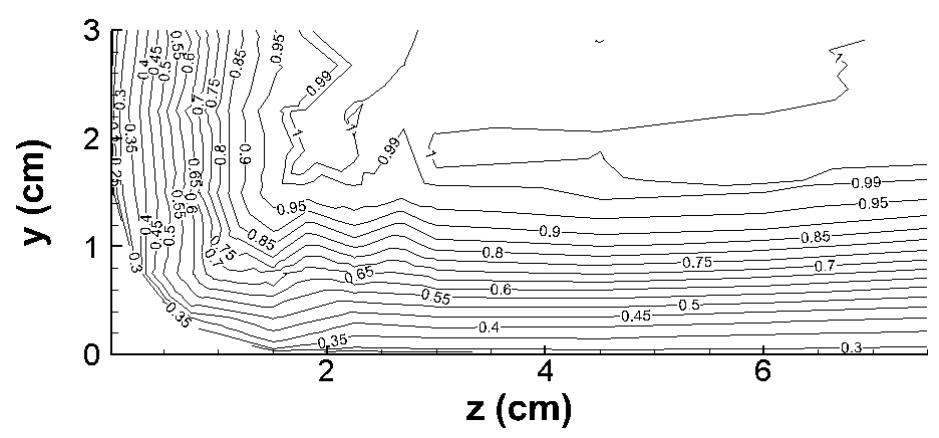

(G) $r / \delta=1.28, I / \delta=0, t / \delta=2.75$

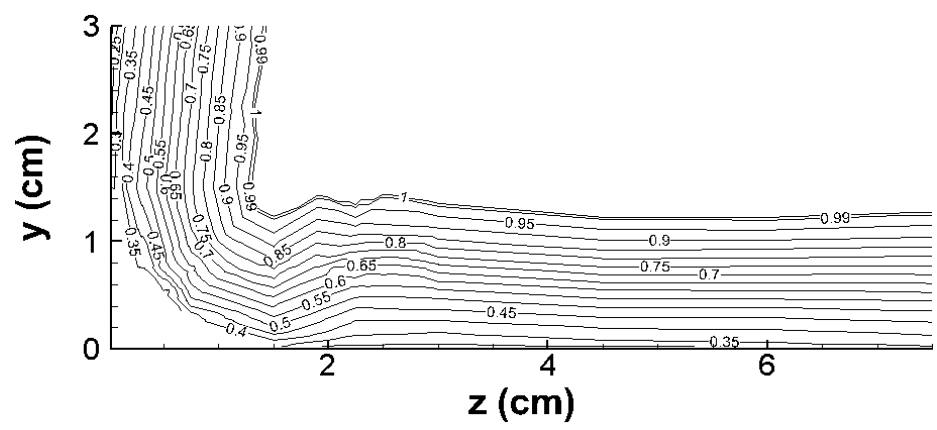

(H) $r / \delta=1.28, I / \delta=22.0, t / \delta=11.0$

FIGURE 25. NORMALIZED ISOVELOCITY CONTOURS FOR THE FILLET CONFIGURATIONS. (CONCLUDED) 


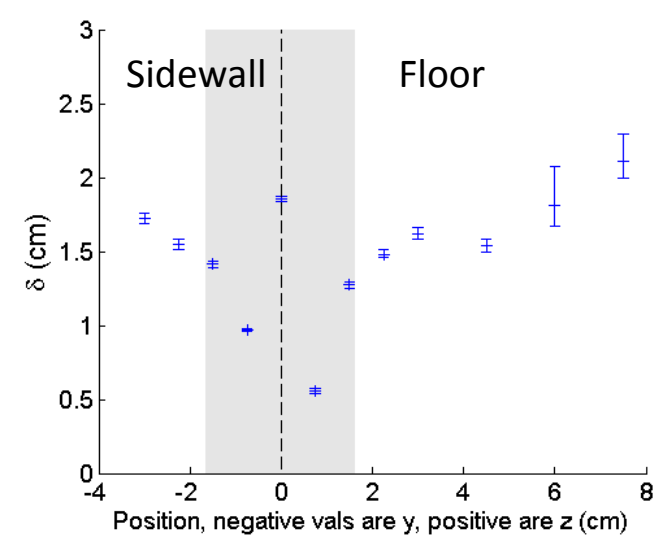

(A) $r / \delta=0.51, l / \delta=0, t / \delta=11.0$

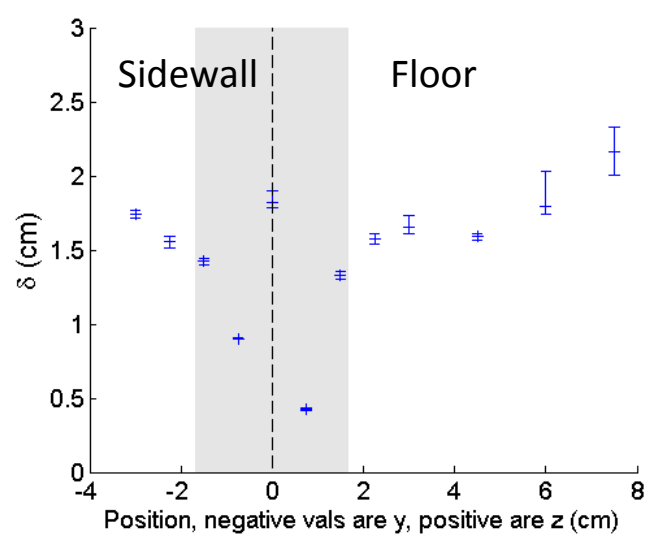

(c) $r / \delta=0.77,1 / \delta=7.35, t / \delta=2.75$

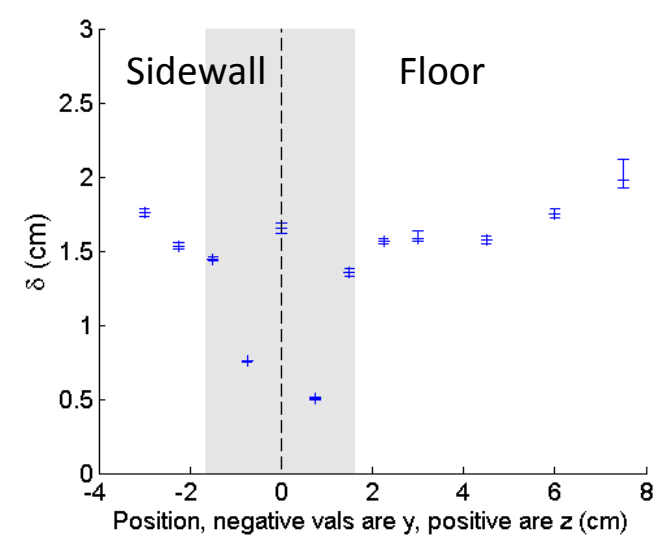

(E) $r / \delta=1.02,1 / \delta=7.35, t / \delta=11.0$

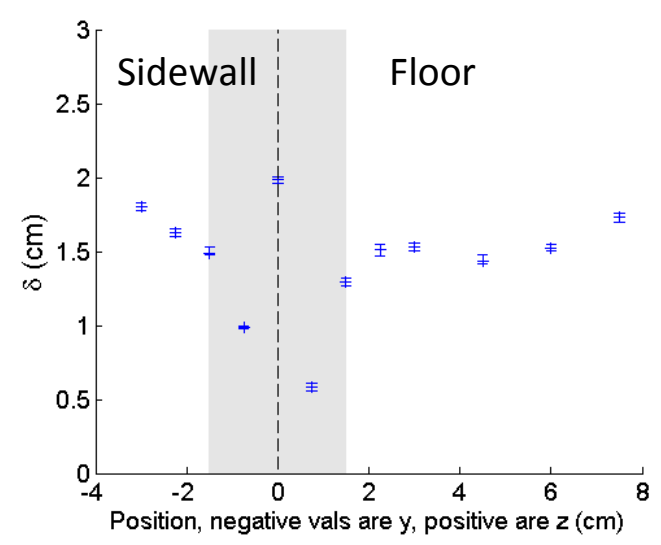

(B) $r / \delta=0.51, l / \delta=22.0, t / \delta=2.75$

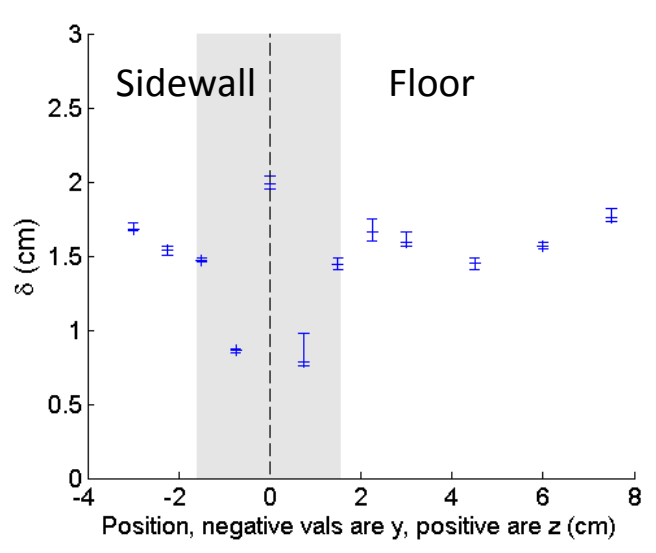

(D) $r / \delta=0.77, I / \delta=14.7, t / \delta=11.0$

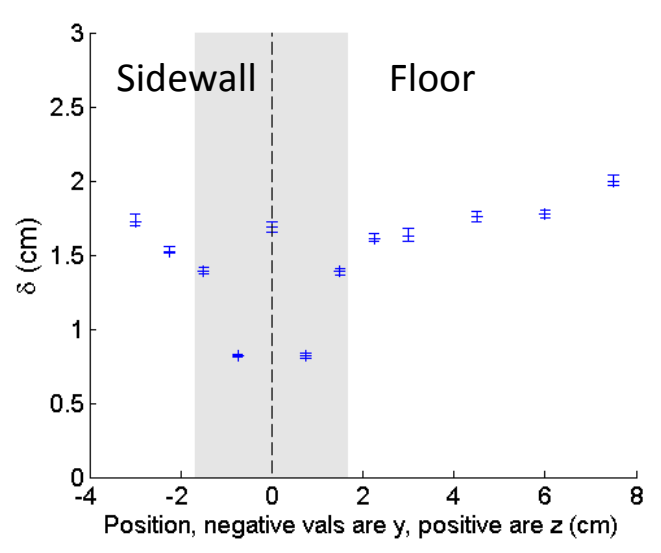

(F) $r / \delta=1.02, I / \delta=14.7, t / \delta=2.75$

FIGURE 26. BOUNDARY-LAYER THICKNESS AT EACH PROFILE LOCATION FOR EACH OF THE FILLET CONFIGURATIONS. 


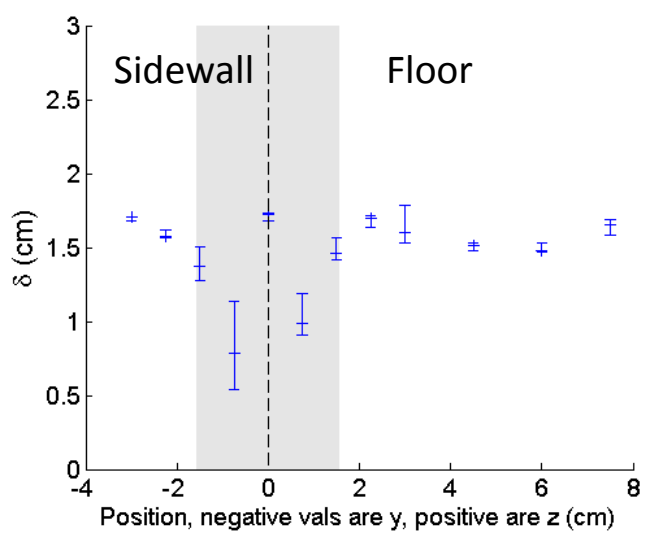

(G) $r / \delta=1.28, I / \delta=0, t / \delta=2.75$

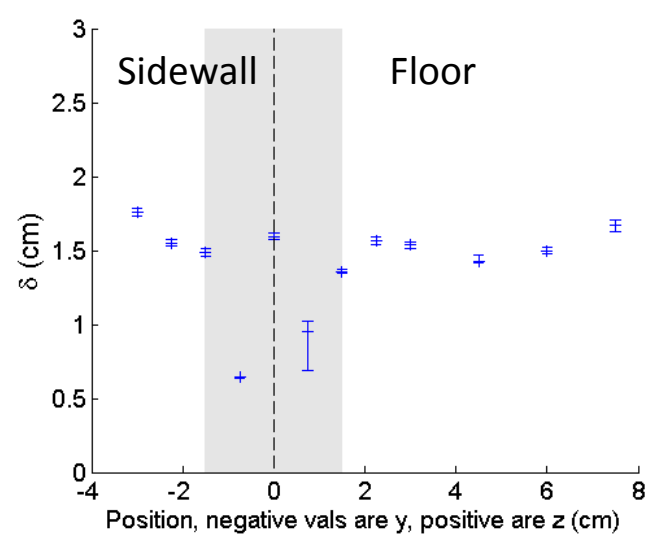

(H) $r / \delta=1.28, I / \delta=22.0, t / \delta=11.0$

FIGURE 26. BOUNDARY-LAYER THICKNESS AT EACH PROFILE LOCATION FOR EACH OF THE FILLET CONFIGURATIONS. (CONCLUDED)

Looking at equivalent plots for the incompressible shape factor at each profile location for each fillet configurations, shown in Figure 27, some trends can be observed. Typically, the lowest measured incompressible shape factor was in the corner region. For the smallest three fillet radii, the shape factor increased moving toward the tunnel centerline, with larger increases seen for the shorter fillet lengths. For the largest radius the levels were more uniform, though the largest incompressible shape factor for these cases was consistently measured at the sidewall profile at $y=3 \mathrm{~cm}$. 


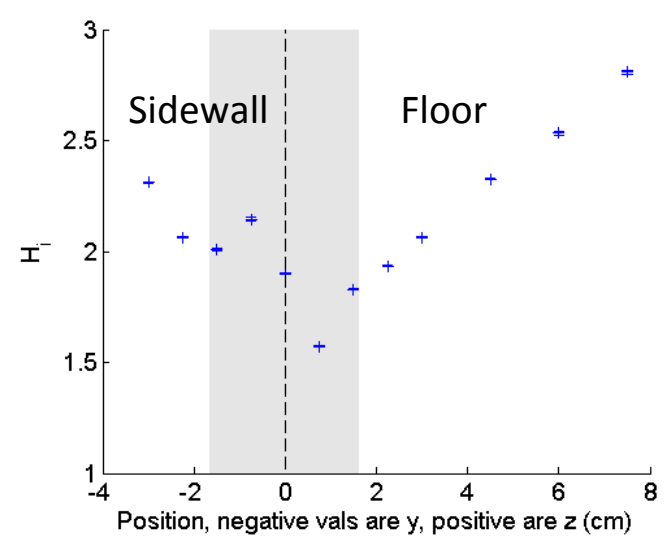

(A) $r / \delta=0.51, l / \delta=0, t / \delta=11.0$

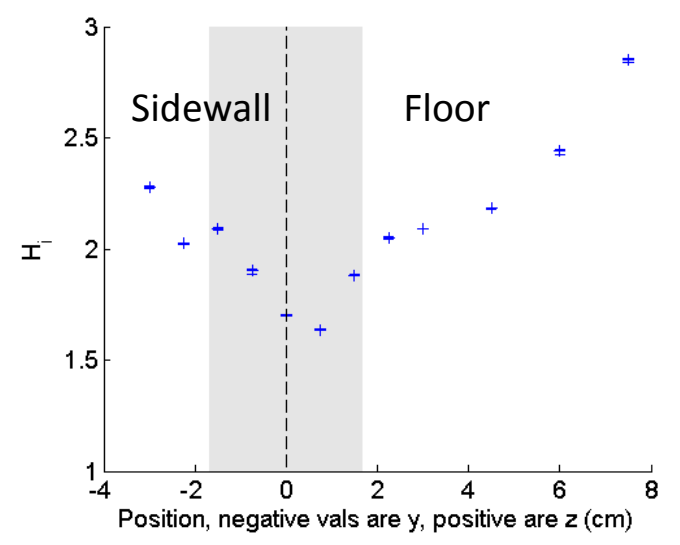

(c) $r / \delta=0.77,1 / \delta=7.35, t / \delta=2.75$

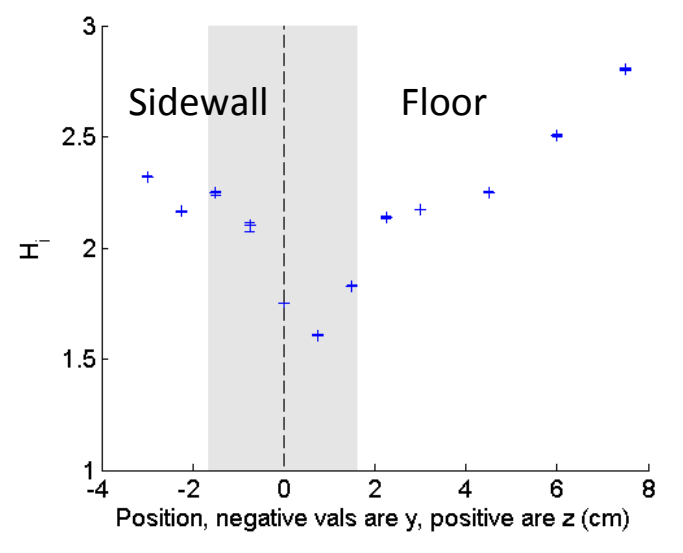

(E) $r / \delta=1.02, I / \delta=7.35, t / \delta=11.0$

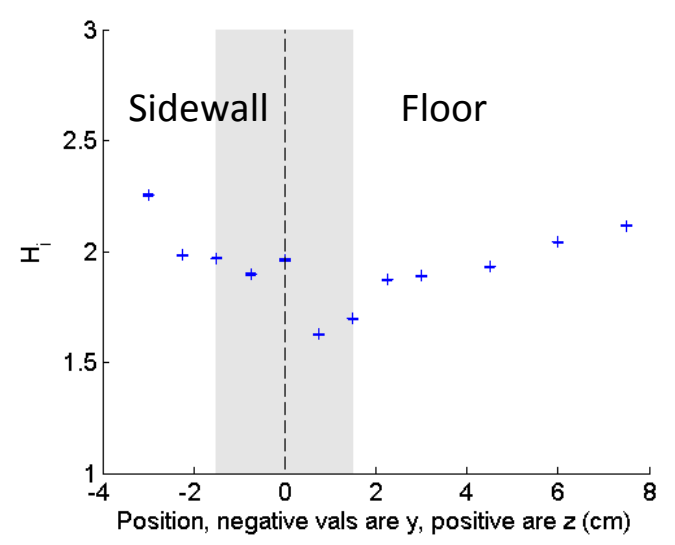

(B) $r / \delta=0.51, l / \delta=22.0, t / \delta=2.75$

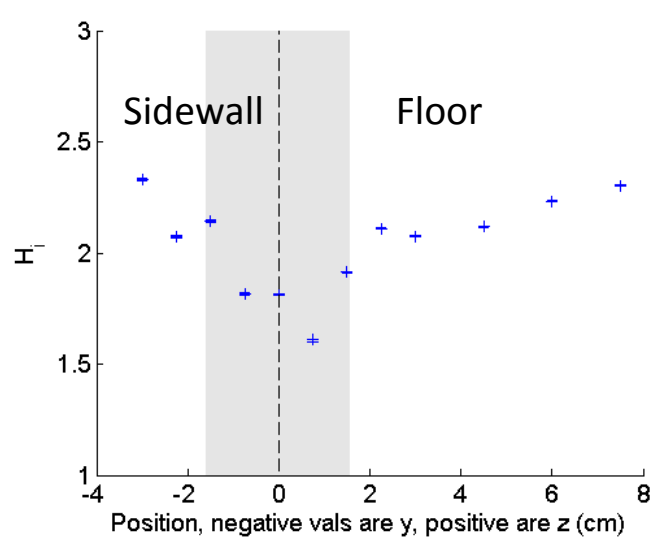

(D) $r / \delta=0.77, I / \delta=14.7, t / \delta=11.0$

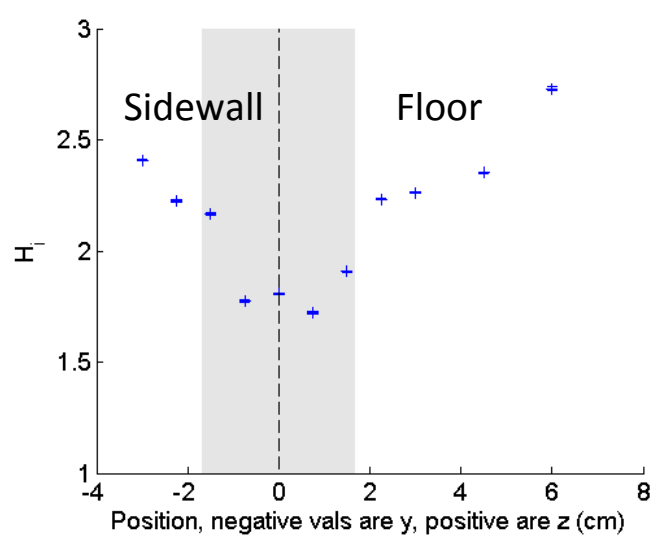

(F) $r / \delta=1.02, I / \delta=14.7, t / \delta=2.75$

FIGURE 27. INCOMPRESSIBLE SHAPE FACTOR AT EACH PROFILE LOCATION FOR EACH OF THE FILLET CONFIGURATIONS. 


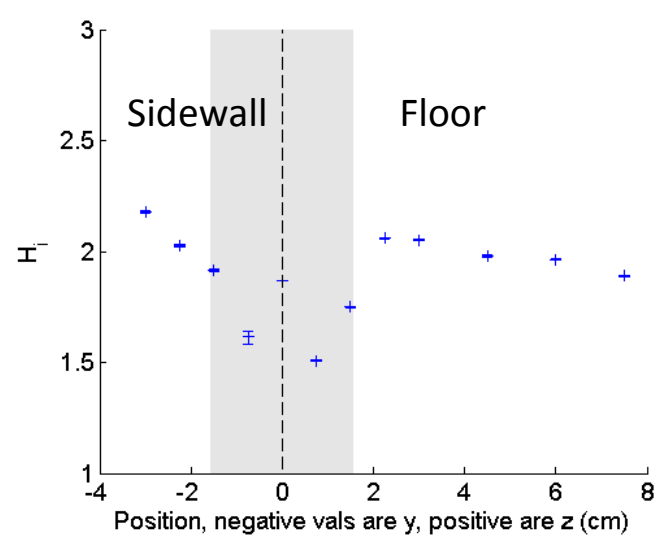

(G) $r / \delta=1.28, I / \delta=0, t / \delta=2.75$

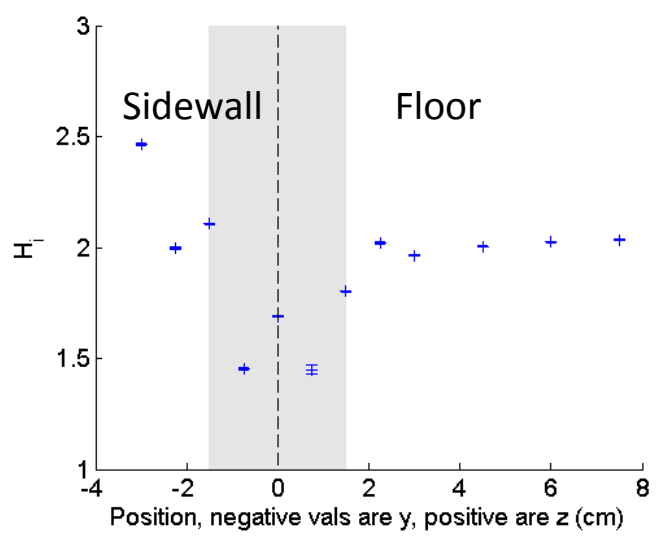

(H) $r / \delta=1.28, I / \delta=22.0, t / \delta=11.0$

FIGURE 27. INCOMPRESSIBLE SHAPE FACTOR AT EACH PROFILE LOCATION FOR EACH OF THE FILLET CONFIGURATIONS. (CONCLUDED)

In order to compare across the cases, the boundary-layer thickness along the corner bisector is shown in Figure 28 for all eight fillet configurations as well as the baseline. All eight fillet configurations resulted in a thinner boundary layer compared to the baseline. Larger fillet radii resulted in thinner boundary layers, as might be expected.

Looking at the effect of fillet length, for each pair at a radius in the figure the open symbol represents the shorter length, I. Interestingly, the shorter cases caused a greater reduction in boundary-layer thickness along the bisector than the longer configurations. The two cases at $r / \delta=1.02$ have a similar magnitude. This may be attributed to the fact that the sum of $I / \delta$ and $t / \delta$ for the two cases was very similar, with combined lengths of 17.45 and 18.35 for the longer and shorter $I / \delta$, respectively. This was not the case for the other fillet configurations. 
Prior to the test, it was anticipated that the configurations with $/ / \delta=0$ would have the least effect on the interaction. However, the benefit of these cases may in part be attributable to the local boundary layer thinning due to stream tube contraction resulting from the compression of the taper acting in the interaction region. This effect is minimal for the $r / \delta=0.51, I / \delta=0, t / \delta=11.0$ case because the small radius and long taper formed at most an angle of 1.1 degrees. This small angle, even using a two-dimensional approximation that is generous, would result in a local stream tube area reduction of 3.2 \%. For the $r / \delta=1.28, I / \delta=0, t / \delta=2.75$ case, however, the compression angle of the taper was 10.9 degrees, resulting in a maximum stream tube area reduction of $24 \%$. Because of the location of the taper, this effect was applied in the interaction region for the $I / \delta=0$ cases. This approximation is optimistic, but suggests that the effect may have locally thinned the boundary layer sufficiently to improve the flow through the interaction region.

Examining the change in the flow field due to the fillets another way, Figure 29 shows the corner boundary-layer edge location versus fillet radius. The boundary layer edge location is calculated as the distance from the 90 degree corner to the boundary layer edge along the corner bisector. For the baseline case where the wall location is equivalent to the 90 degree corner, the boundary layer edge location is equal to the boundary layer thickness, $\delta$. Examining the results in this way shows that the physical location of the boundary layer edge changes relatively little throughout all of the configurations, so the thinning of the boundary layer is due to the lowest momentum region in the corner being filled in by the fillet. While the changes are small, it is interesting to note that for six of 
the eight cases, the boundary layer edge location has actually decreased with the introduction of the corner fillets. The largest increase in boundary layer edge location was measured for the $r / \delta=1.28, I / \delta=22.0, t / \delta=11.0$ fillet configuration, with an increase from $2.33 \mathrm{~cm}$ for the baseline configuration to $2.38 \mathrm{~cm}$.

In trade for the benefits seen in the corner, Figure 30 shows the boundary layer thickening that occurred on the tunnel centerline $(z=7.5 \mathrm{~cm})$ compared to the baseline case for all eight fillet configurations. The three smallest fillet radii caused similar levels of thickening at the centerline. For the smallest two radii, the length also played a factor, with larger centerline boundary-layer thicknesses occurring for shorter fillet lengths. Again, the magnitude of the boundary-layer thickness was similar for both cases with $r / \delta$ $=1.02$ where the combined length including the fillet and taper were nearly equal. On the centerline, the largest radius had the least negative impact. The boundary-layer thickness increased from $1.51 \mathrm{~cm}$ for the baseline to 1.66 for the large radius cases. Overall, of the configurations tested, the large radius seems to give the best combination of control in the corner, evidenced by reduction in boundary-layer thickness, coupled with minimal impacts at the tunnel centerline. 


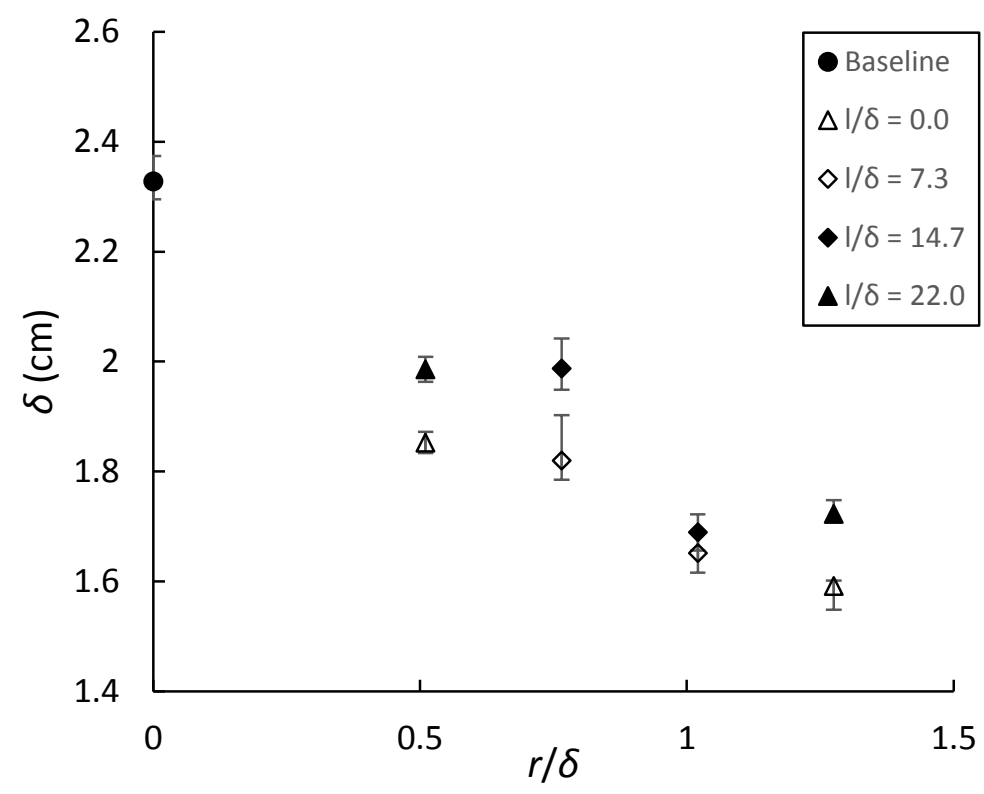

FIGURE 28. BOUNDARY-LAYER THICKNESS ALONG THE CORNER BISECTOR VERSUS FILLET RADIUS.

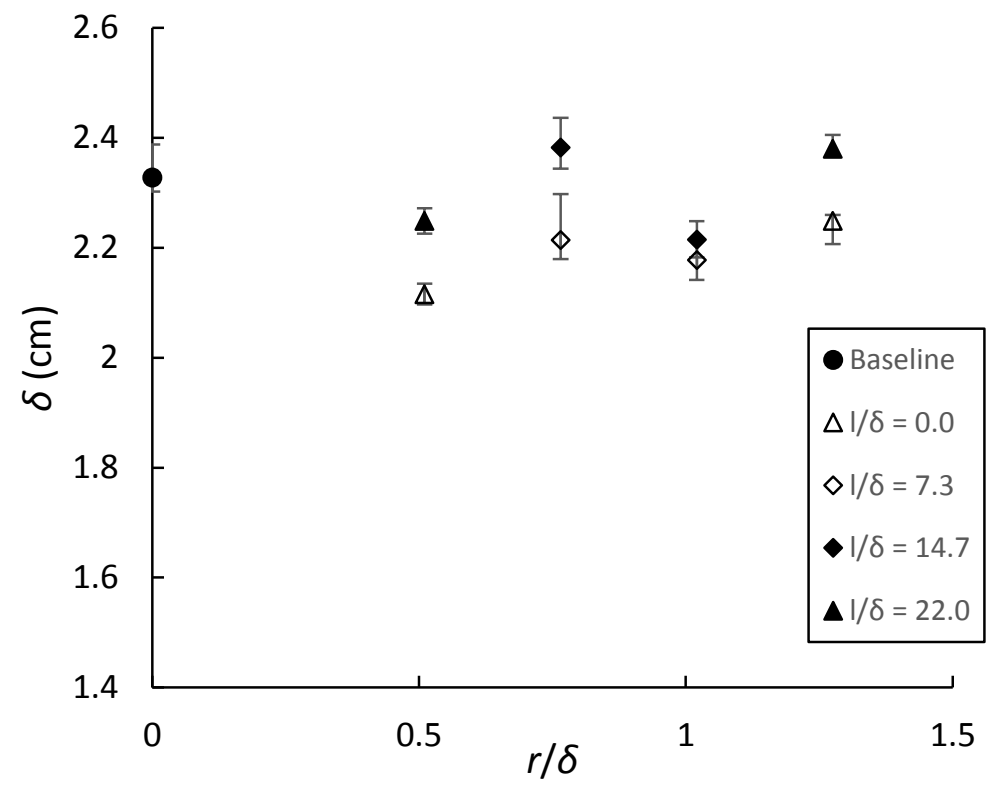

FIGURE 29. BOUNDARY LAYER EDGE LOCATION MEASURED ALONG THE CORNER BISECTOR VERSUS FILLET RADIUS. 


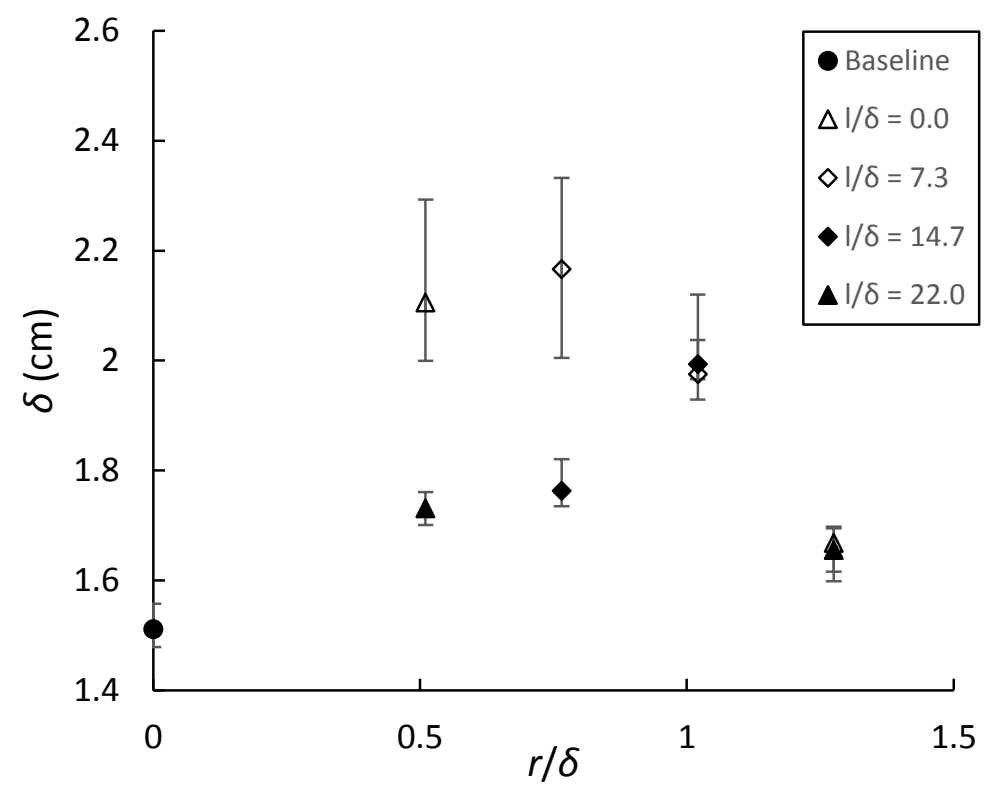

FIGURE 30. BOUNDARY-LAYER THICKNESS AT THE TUNNEL CENTERLINE VERSUS FILLET RADIUS.

Looking at the incompressible shape factor for the corner profile versus fillet radius in Figure 31, the fillets caused a small reduction. This indicates an increased resistance to flow separation. Figure 32 shows the effect on incompressible shape factor at the tunnel centerline. The three smallest fillet radii produce a large increase in the incompressible shape factor at the centerline. Again, the largest fillet configuration shows less adverse impact at the centerline. In this case the longer fillets at the largest radii have the least impact with an increase in incompressible shape factor from 1.62 for the baseline to 1.89 . 


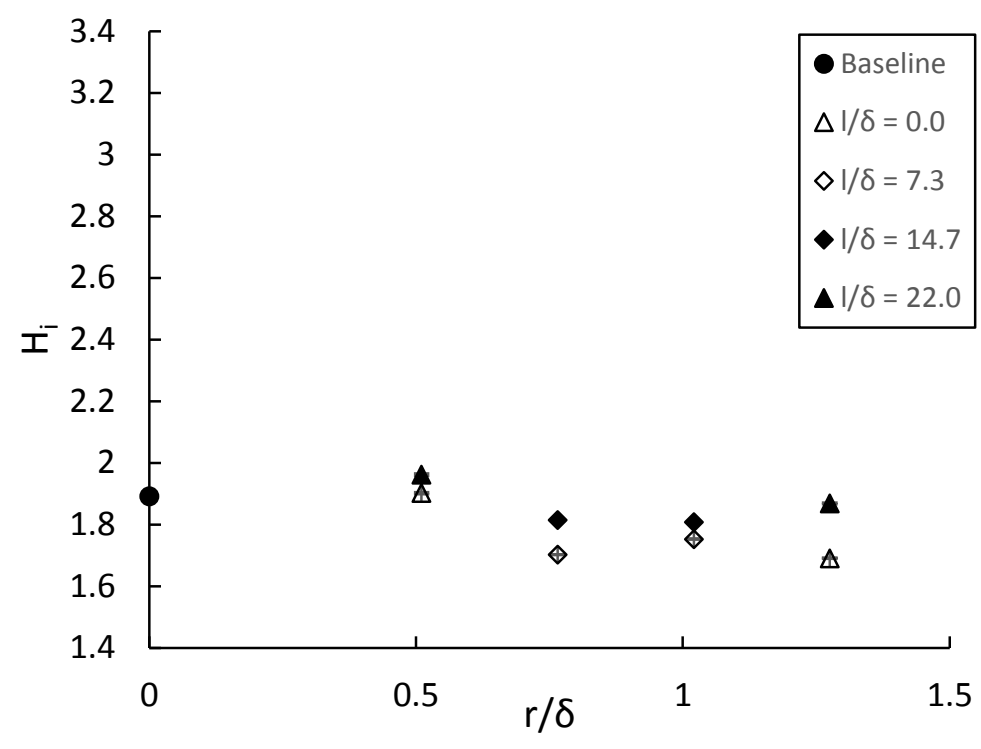

FIGURE 31. INCOMPRESSIBLE SHAPE FACTOR FOR THE CORNER PROFILE VERSUS FILLET RADIUS.

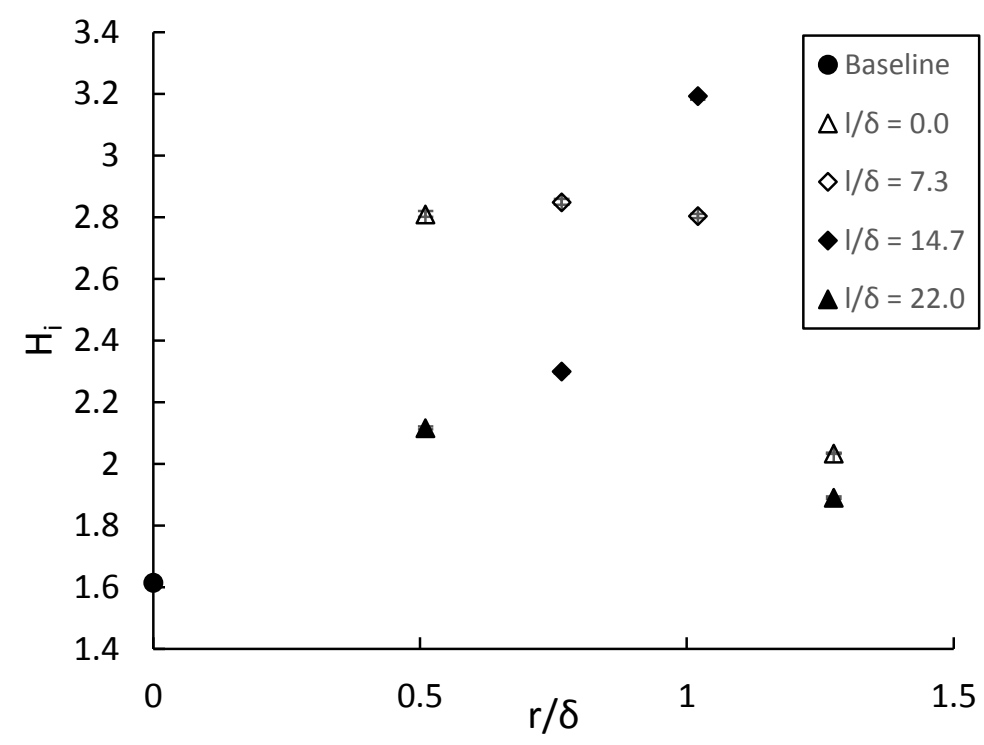

FIGURE 32. INCOMPRESSIBLE SHAPE FACTOR AT THE TUNNEL CENTERLINE VERSUS FILLET RADIUS

Oil flow visualization was only captured for two of the fillet configurations. Figure 33 shows the resulting images compared to the oil flow for the baseline case. The solid line 
in each figure indicates the calculated inviscid shock impingement location. The dashed lines show the extent of the interaction region in the corners and along the centerline for the baseline case to allow comparison between the images. Because the oil did not flow well on the EXAMIX material, it is somewhat difficult to observe the effect of the fillet on the corner region.

For the $r / \delta=0.51, I / \delta=0, t / \delta=11.0$ case, it can be seen that the upstream extent of the interaction region across the span has moved downstream. Additionally, the angle of the oil flow which follows the corner separation appears shallower. For the $r / \delta=1.02,1 / \delta$ $=14.7, t / \delta=2.75$ case, the oil flow patterns are very similar to those observed for the baseline case. 


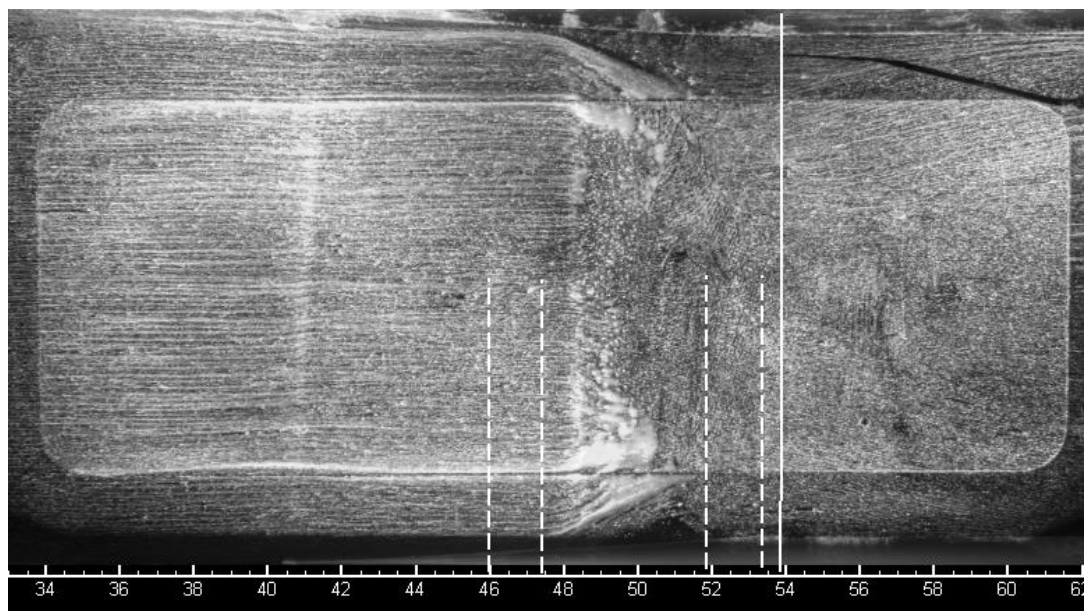

(A) $r / \delta=0.51, I / \delta=0, t / \delta=11.0$

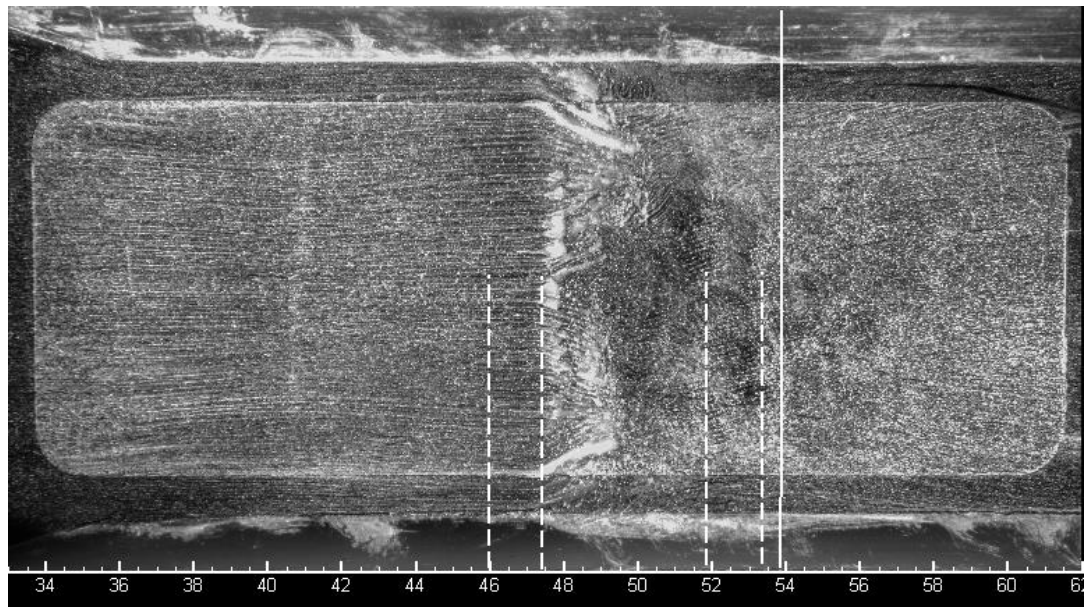

(B) $r / \delta=1.02, I / \delta=14.7, t / \delta=2.75$

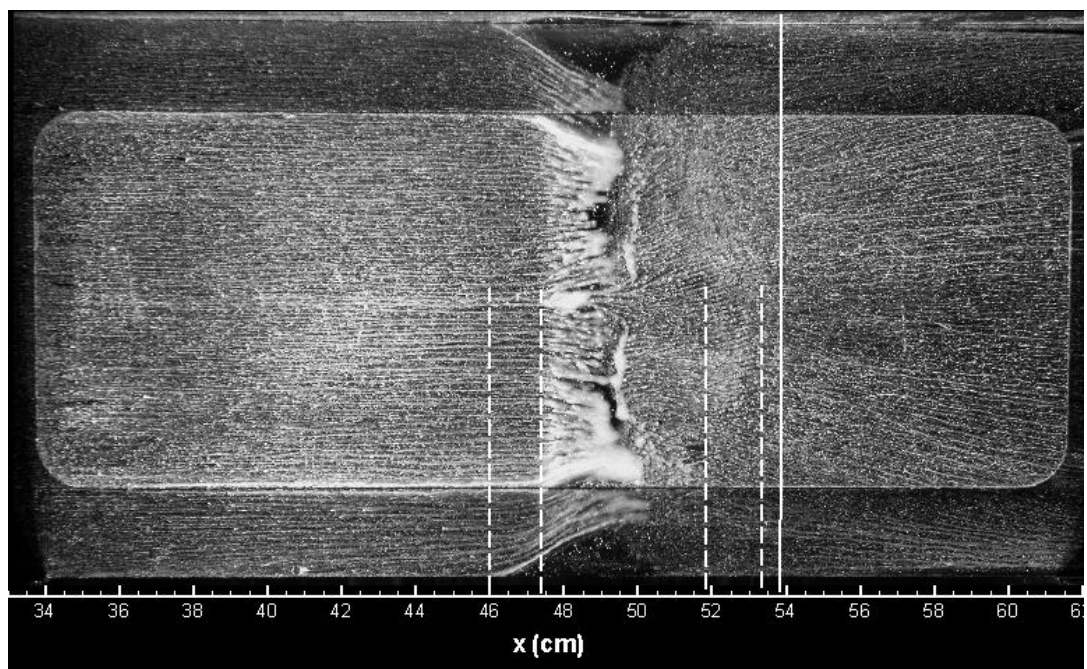

(c) BASELINE

FIGURE 33. OIL FLOW VISUALIZATION FOR TWO FILLET CONFIGURATIONS COMPARED TO THE BASELINE. THE SOLID LINE INDICATES THE INVISCID SHOCK IMPINGEMENT LOCATION. THE DASHED LINES INDICATE THE EXTENT OF THE SEPARATION REGION FOR THE BASELINE CASE. 


\section{Fillets with Micro-ramp Flow Control}

One configuration was tested with the $r / \delta=1.28, \quad / / \delta=22.0, t / \delta=11.0$ fillet configuration for control of the corner interaction coupled with micro-ramp flow control along the tunnel floor. The isovelocity contours are shown in Figure 34 for the identical fillet configuration with and without micro-ramps. Part A of the figure is repeated from the previous section for comparison. The effect of the vortices generated by the microramps can be seen in the characteristic arches of the isovelocity lines typical for vortex generators.

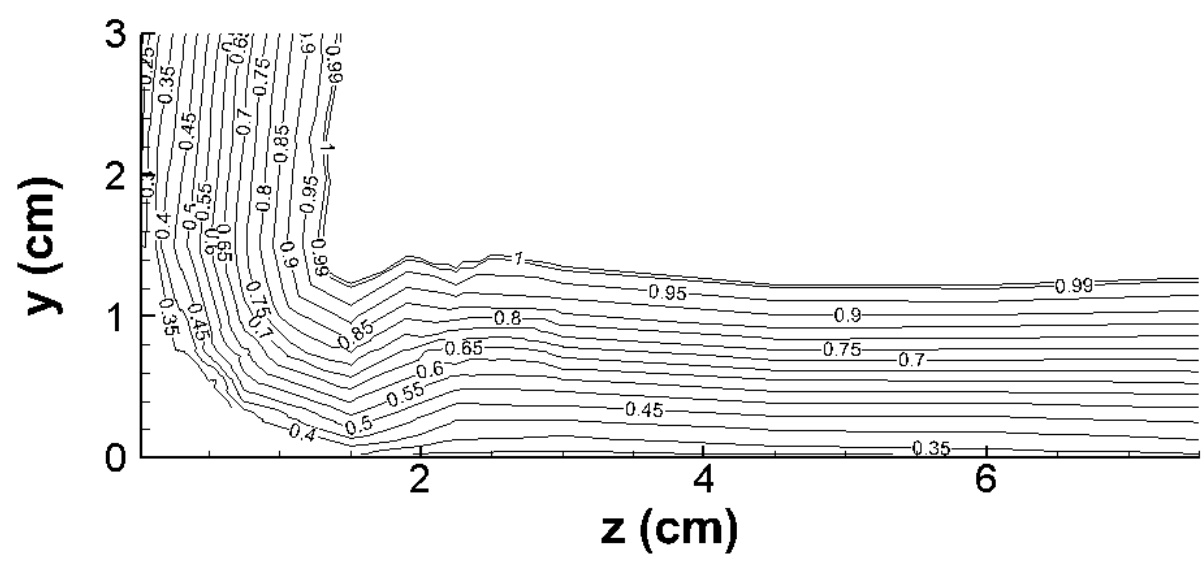

(A) $r / \delta=1.28, I / \delta=0, t / \delta=2.75$ WITHOUT MICRO-RAMPS

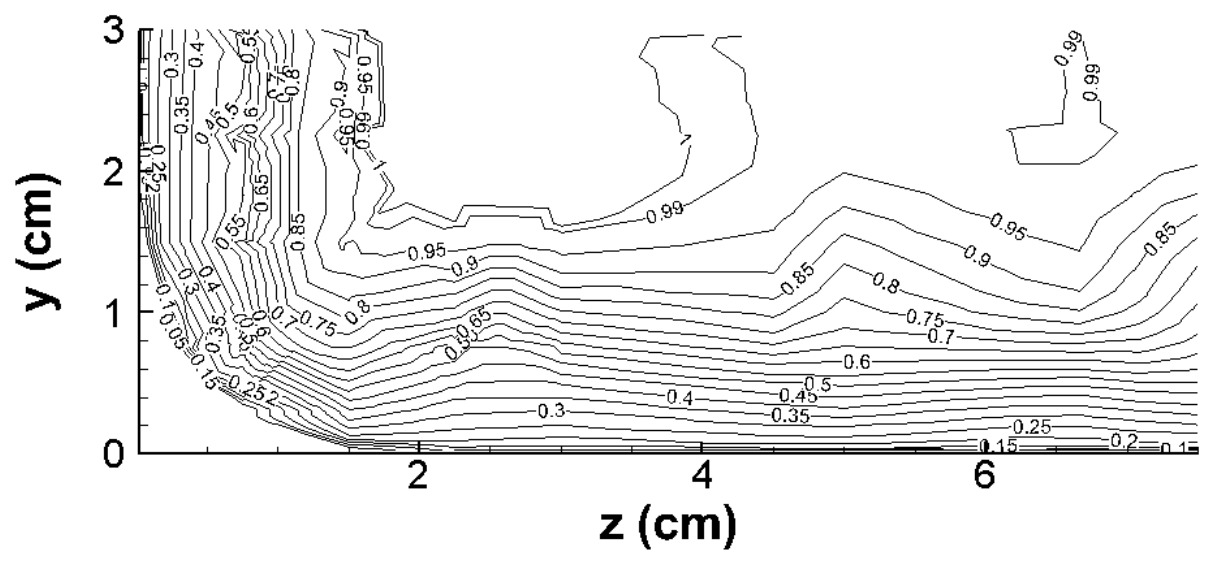

(B) $r / \delta=1.28, I / \delta=0, t / \delta=2.75$ WITH MICRO-RAMPS

FIGURE 34. NORMALIZED ISOVELOCITY CONTOURS COMPARING WITH AND WITHOUT MICRO-RAMPS. 
The boundary-layer thickness at each profile location for the micro-ramp configuration is shown in Figure 35, with the location and height of the micro-ramps indicated as triangles along the abscissa. The values for the boundary layer profiles near the corner that were embedded within the boundary layer of the adjacent wall have been removed from these figures. For this particular combination of micro-ramps and corner fillets, the micro-ramps caused the boundary layer to thicken across the entire measurement plane. In the corner there was little change - the boundary layer thickened from $1.22 \mathrm{~cm}$ with only fillets to $1.24 \mathrm{~cm}$ with the combined control. The incompressible shape factor at each profile location is shown in Figure 36. Compared to the fillet only case, it is also increased throughout the measurement plane.

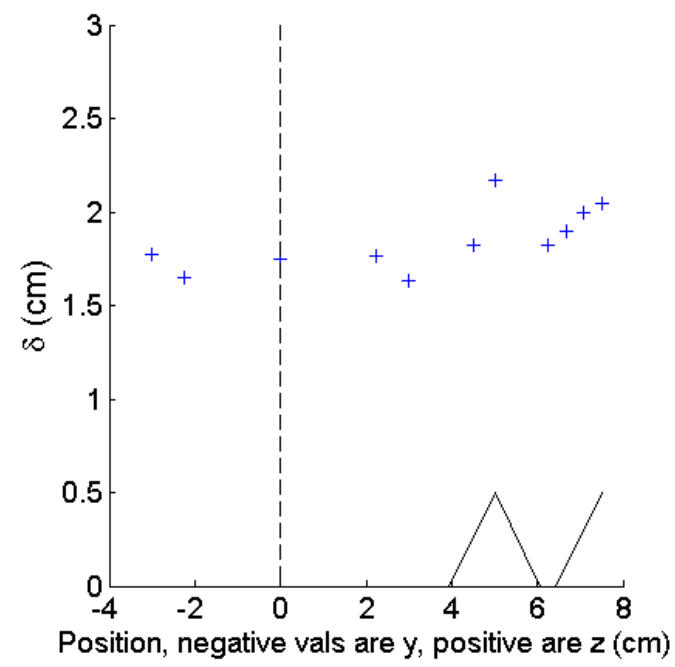

FIGURE 35. BOUNDARY-LAYER THICKNESS AT EACH PROFILE LOCATION FOR THE MICRO-RAMP CASE. 


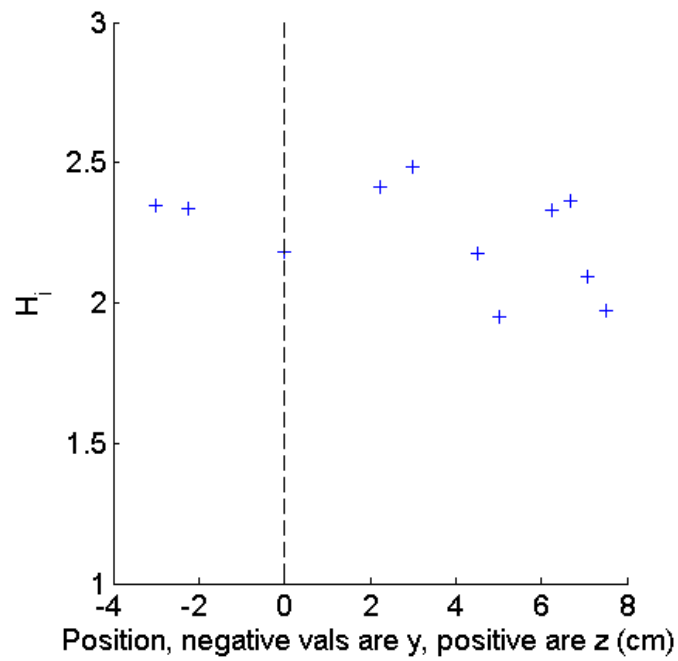

FIGURE 36. INCOMPRESSIBLE SHAPE FACTOR AT EACH PROFILE LOCATION FOR THE MICRO-RAMP CASE. 


\section{Conclusions and Future Work}

The shock-wave/boundary-layer interaction tested included three distinct unit problems: a swept fin interaction, an impinging oblique shock-wave interaction, and a corner interaction. The corner interaction was the focus of this study.

Each of the elements of the configuration produced an effect in the corner region. The swept fin interaction turned the flow on the sidewall toward the floor, driving additional low momentum fluid into the corner region. The impinging shock interaction had a greater static pressure rise than the swept fin interaction because the oblique shock and its reflection encountered the floor boundary layer in the same region. The effect of the viscous wall was to distribute this interaction region. This pressure rise across both the shock and reflection was also experienced in the corner. Because the wall shear in the corner must be zero (at $y=0, \partial u / \partial z=0$ ), the corner was in a state of incipient separation. This also resulted in a thick subsonic layer in the corner through which the pressure rise could propagate.

Because of this combination of influences, the corner region is the first to separate, and the large subsonic region allows the effect to extend upstream. In order to attempt to control the interaction in the corner region, corner fillets were applied with various radii, fillet lengths, and taper length from square to the full fillet radius.

Fillets were observed to be effective in reducing the boundary-layer thickness in the corner downstream of an oblique shock. There was an associated penalty in the form of increased boundary-layer thickness at the tunnel centerline. The fillets effected control 
on the corner boundary layer through a reduction in the thickness of the subsonic layer in the corner, as well as by removing the enforced region of localized zero wall shear stress. Additionally, for the $I / \delta=0$ cases, a benefit may have been gained from the effect of a localized reduction in boundary-layer thickness due to stream tube contraction from the compression created by the taper.

Comparing the results for the eight cases, it was found that a larger radius caused a greater reduction in boundary-layer thickness along the corner bisector. To a lesser, but measureable, extent the shorter fillet lengths resulted in thinner corner boundary layers. At the centerline, boundary layer thickening was seen for all of the cases. The largest fillet radius resulted in the least negative impact at the centerline. Little effect of taper was noted. Overall, of the configurations tested the large radius seemed to give the best combination of control in the corner, evidenced by reduction in boundary-layer thickness, coupled with minimal impacts at the tunnel centerline.

Because of limits in test time and funding, only one fillet configuration with microramps was able to be tested. The configuration tested showed no benefits from the micro-ramps, and in fact both the boundary layer thickness and incompressible shape factor were increased across the measurement plane indicating a negative impact from the devices. The strong vortices produced by the micro-ramps did not have a significant negative impact on the corners. It is possible that another configuration would be more favorable. 
In this phase, only a limited number of fillet configurations and measurement locations were possible. Many interesting avenues of further research exist in this area.

One item that was originally planned, but later deleted from the current test was measurements of the boundary-layer growth along the length of the fillets without the shock interaction. Additional information on the flow field entering the interaction region when the fillets are installed could help better understand the flow control mechanisms.

Because the largest radius of the fillets tested produced the most promising results, it would be worthwhile to include a larger fillet radius in future testing. Filling in more of the configurations within the range of the variables tested would also be beneficial, as it is recognized that the current matrix is sparse.

Other measurement planes in the interaction region or the inclusion of additional measurement techniques could add depth to the data set and facilitate a better understanding.

Finally, tests incorporating additional shock strengths including weaker interactions more representative of those found in supersonic inlet designs would be of interest. 


\section{Bibliography}

[1] B. Oskam, I. E. Vas and S. M. Bogdonoff, "An Experimental Study of ThreeDimensional Flow Fields in an Axial Corner at Mach 3," in 10th AIAA Fluid and Plasmadynamics Conference, Albuquerque, NM, 1977.

[2] S. M. Bogdonoff and K. Poddar, "An Explanatory Study of a Three-Dimensional Shock Wave Turbulent Boundary Layer Interaction in a Corner," in 29th AIAA Aerospace Sciences Meeting, Reno, NV, 1991.

[3] B. Morgan, S. Kawai and S. K. Lele, "Large-Eddy Simulation of an Oblique Shock Impinging of a Turbulent Boundary Layer," in 40th Fluid Dynamics Conference, Chicago, IL, 2010.

[4] J. A. Benek, C. J. Suchyta, III and H. Babinsky, "The Effect of Wind Tunnel Size on Incident Shock Boundary Layer Interaction Experiments," in 51st AIAA Aerospace Sciences Meeting, Grapevine, TX, 2013.

[5] P. Batcho and J. Sullivan, "The 3-D Flowfield in a Supersonic Shock Boundary Layer Corner Interaction," in 26th AIAA Aerospace Sciences Meeting, Reno, NV, 1988.

[6] A. B. Oliver, R. P. Lillard, G. A. Blaisdell and A. S. Lyrintzis, "Effects of ThreeDimensionality in Turbulent Compression Ramp Shock-Boundary Layer Interaction Computations," in 46th AIAA Aerospace Sciences Meeting, Reno, NV, 2008. 
[7] R. M. Chriss, T. G. Keith, W. R. Hingst, A. J. Strazisar and A. R. Porro, "An LDA Investigation of Three-Dimensional Normal Shock Boundary Layer Interactions in a Corner," in 19th AIAA Fluid Dynamics, Plasma Dynamics and Lasers Conference, Honolulu, $\mathrm{HI}, 1987$.

[8] T. Handa, M. Masuda and K. Matsuo, "Three-Dimensional Normal ShockWave/Boundary-Layer Interaction in a Rectangular Duct," AIAA Journal, vol. 43, no. 10, pp. 2182-2187, 2005.

[9] J. S. Shang, W. L. Hankey and J. S. Petty, "Three-Dimensional Supersonic Interacting Turbulent Flow Along a Corner," in AIAA 11th Fluid and Plasma Dynamics Conference, Seattle, WA, 1978.

[10] F. Marconi, "Internal Corner Flow Fields," in 17th Aerospace Sciences Meeting, New Orleans, LA, 1979.

[11] S. G. Rubin, "Incompressible flow along a corner," Journal of Fluid Mechanics, vol. 26, no. 1, pp. 97-110, 1966.

[12] K. N. Ghia and R. T. Davis, "A Study of Compressible Potential and Asymptotic Viscous Flows for Corner Regions," AIAA Journal, vol. 12, no. 3, pp. 355-359, 1974.

[13] A. G. Mikhail and K. N. Ghia, "Study of Viscous Compressible Flow Along an Axial Corner," in AIAA 10th Fluid and Plasmadynamics Conference, Albuquerque, NM, 1977. 
[14] J. S. Shang and W. L. Hankey, "Numerical Solution of the Navier-Stokes Equations for a Three-Dimensional Corner," AIAA Journal, vol. 15, no. 11, pp. 1575-1582, 1977.

[15] M. Zamir and A. D. Young, "Experimental Investigation of the Boundary Layer in a Streamwise Corner," The Aeronautical Quarterly, vol. 21, pp. 313-339, 1970.

[16] O. O. Mojola and A. D. Young, "An Experimental Investigation of the Turbulent Boundary Layer along a Streamwise Corner," in AGARD Conf Proc 93, Turbulent Shear Flows, 1971.

[17] A. Melling and J. H. Whitelaw, "Turbulent flow in a rectangular duct," Journal of Fluid Mechanics, vol. 78, no. 2, pp. 289-315, 1976.

[18] I. Nakamura, M. Miyata, T. Kushida and Y. Kagiya, "An Experimental Study of the Intermittent Region of a Corner Turbulent Boudary Layer," JSME International Journal, vol. 30, no. 259, pp. 72-79, 1987.

[19] D. O. Davis, F. B. Gessner and G. D. Kerlick, "Experimental and Numerical Investigation of Supersonic Turbulent Flow Through a Square Duct," AIAA Journal, vol. 24, no. 9, pp. 1508-1515, 1986.

[20] D. O. Davis and F. B. Gessner, "Further Experiments on Supersonic Turbulent Flow Development in a Square Duct," AIAA Journal, vol. 27, no. 8, pp. 1023-1030, 1989. 
[21] M. Mani, D. A. Babcock, C. M. Winkler and P. R. Spalart, "Predictions of Supersonic Turbulent Flow in a Square Duct," in 51st AIAA Aerospace Sciences Meeting, Grapevine, TX, 2013.

[22] A. G. Mikhail and K. N. Ghia, "Viscous Compressible Flow in the Boundary Region of an Axial Corner," AIAA Journal, vol. 16, no. 9, pp. 931-939, 1978.

[23] L. Prandtl, Essentials of Fluid Dynamics, New York: Hafner Publishing Co., 1952.

[24] V. I. Kornilov, "Issledvanie prostranstvennogo techeniya v uglovoj konfiguratsii v usloviyakh vzaimodejstviya s radayushchim kosym skachkom uplotneniya," Russian Academy of Sciences, Novosibirsk, 1992.

[25] W. E. Eagle, J. F. Driscoll and J. A. Benek, "Experimental Investigation of Corner Flows in Rectangular Supersonic Inlets with 3D Shock-Boundary Layer Effects," in 49th AIAA Aerospace Sciences Meeting, Orlando, FL, 2011.

[26] D. Barruzini, N. Domel and D. N. Miller, "Addressing Corner Interactions Generated by Oblique Shock-Waves in Unswept Right-Angle Corners and Implications for HighSpeed Inlets," in 50th AIAA Aerospace Sciences Meeting, Nashville, TN, 2012.

[27] P. J. K. Bruce, D. M. F. Burton, N. A. Titchener and H. Babinsky, "Corner effect and separation in transonic channel flows," Journal of Fluid Mechanics, vol. 679, pp. 247$262,2011$. 
[28] R. M. Chriss, W. R. Hingst, A. J. Strazisar and T. G. Keith, "An LDA Investigation of Three-Dimensional Normal Shock Wave Boundary-Layer Interactions," NASA Transonic Symposium: Theory, Application, and Experiment, 1989.

[29] D. M. F. Burton, H. Babinsky and P. J. K. Bruce, "Experimental Investigation into Parameters Governing Corner Interactions for Transonic Shock Wave/Boundary Layer Interactions," in 48th AIAA Aerospace Sciences Meeting, Orlando, FL, 2010.

[30] P. J. K. Bruce, H. Babinsky, B. Tartinville and C. Hirsch, "Corner Effect and Asymmetry in Transonic Channel Flows," AIAA Journal, vol. 49, no. 11, pp. 2382-2392, 2011.

[31] A. S. Valerino, "Effects of Internal Corner Fillets on Pressure Recovery - Mass Flow Characteristics of Scoop-Type Conical Supersonic Inlets," NACA RM E52J10, Cleveland, $\mathrm{OH}, 1952$.

[32] L. Shi and R. W. Guo, "Serpentine Inlet Design and Analysis," in 50th AIAA Aeropace Sciences Meeting, Nashville, TN, 2012.

[33] J. L. Mark, M. A. McGarry and P. V. Reagan, "Research on a Two-Dimensional Inlet for a Supersonic V/STOL Propulsion System," NASA CR-174945, Cleveland, OH, 1989.

[34] W. P. Wang, R. S. Lin, M. R. Malik and J. R. Edwards, "Control of Corner Flow Vortices by Geometric Shaping in Mach 2.4 Rectangular Nozzles," in 15th Applied Aerodynamics Conference, 1997. 
[35] W. J. Devenport, N. K. Agarwal, M. B. Dewitz, R. L. Simpson and K. Poddar, "Effects of Fillets on the Flow Past a Wing-Body Junction," AIAA Journal, vol. 28, no. 12, pp. 2017-2024, 1990.

[36] S. A. Fisher, "Three-Dimensional Flow Effects in a Two-Dimensional Air Intake," Journal of Propulsion, vol. 2, no. 6, pp. 546-551, 1986.

[37] N. Titchener, P. Bruce and H. Babinsky, "An Experimental Investigation of Corner Bleed Applied to a Normal Shock-Wave / Boundary-Layer Interaction and Diffuser," in 49th AIAA Aerospace Sciences Meeting, Orlando, FL, 2011.

[38] A. S. Toby and S. M. Bogdonoff, "An Exploratory Study of Corner Bleed of a Fin Generated Three-Dimensional Shock Wave Turbulent Boundary Layer Interaction," in 27th AIAA Aerospace Sciences Meeting, Reno, NV, 1989.

[39] G. S. Settles, T. J. Fitzpatrick and S. M. Bogdonoff, "Detailed Study of Attached and Separated Compression Corner Flowfields in High Reynolds Number Supersonic Flow," AIAA Journal, vol. 17, no. 6, pp. 579-585, 1979.

[40] B. P. Willis, D. O. Davis and W. R. Hingst, "Flowfield Measurements in a Normal-HoleBled Oblique Shock-Wave and Turbulent Boundary-Layer Interaction," in 31st AIAA/SAE/ASME/ASEE Joint Propulsion Conference, San Diego, CA, 1995. 
[41] D. R. Smith and A. J. Smits, "The Effects of Successive Distortions on a Turbulent Boundary Layer in Supersonic Flow," Journal of Fluid Mechanics, vol. 351, pp. 253288, 1997.

[42] T. Nguyen, M. Vukovic, M. Behr and B. Reinartz, "Numerical Simulations of Successive Distortions in Supersonic Turbulent Flow," AIAA Journal, vol. 50, no. 11, pp. 2365-2375, 2012.

[43] A. Braafladt, J. Lucero and S. Hirt, "Investigation of Materials for Boundary Layer Control in a Supersonic Wind Tunnel," in MFPT Conference, Cleveland, OH, 2013.

[44] S. M. Hirt and B. Anderson, "Experimental Investigation of the Application of Microramp Flow Control to an Oblique Shock Interaction," in 47th AIAA Aerospace Sciences Meeting, Orlando, FL, 2009.

[45] S. M. Hirt, D. Reich and M. O'Connor, "Microramp Flow Control for Oblique Shock Interactions: Comparison of Computational and Experimental Data," in 5th Flow Control Conference, Chicago, IL, 2010. 